\title{
1 Evolutionary dynamics of specialization in herbivorous stick insects
}

2

3

4

5
Larose Chloé $^{1 *}$, Rasmann Sergio ${ }^{2}$, Schwander Tanja $^{1}$

${ }^{1}$ Department of Ecology and Evolution, University of Lausanne, Switzerland

${ }^{2}$ Institute of Biology, University of Neuchatel, Rue Emile-Argand 11, CH-2000 Neuchâtel, Switzerland

*Corresponding author: chloe.larose@ unil.ch, Tel +41 2169241 81; Fax: +41 216924165

Keywords: Chaparral biome, host shift, plant-herbivore interaction, plant secondary metabolites, realized versus fundamental niche, redwood, Timema stick insect.

Statement of authorship: CL and TS designed the study. CL, SR and TS collected data and CL analyzed the results. All authors contributed to the manuscript.

Data accessibility statement: The data supporting the results will be archived in an appropriate public repository such as Dryad and the data DOI will be included at the end of the article.

Type of article: Letter

Number of words: 150 (abstract), 4805 (main text)

2 Number of references: 108

Number of figures: 4

4 Number of tables: 1 


\section{Abstract}

36 Understanding the evolutionary dynamics underlying herbivorous insect mega-diversity 37 requires investigating the ability of insects to shift and adapt to different host plants. Feeding experiments with nine related stick insect species revealed that insects retain the ability to use ancestral host plants after shifting to novel hosts, with host plant shifts generating fundamental

40 feeding niche expansions. These expansions were not accompanied by expansions of the 41 realized feeding niches however, as species on novel hosts are generally ecologically 42 specialized. For shifts from angiosperm to chemically challenging conifer hosts, generalist 43 fundamental feeding niches even evolved jointly with strong host plant specialization, 44 indicating that host plant specialization is more likely driven by species interactions than by 45 constraints imposed by plant chemistry. By coupling analyses of plant chemical compounds, 46 fundamental and ecological feeding niches in multiple insect species, we provide novel insights into the evolutionary dynamics of host range expansion and contraction in herbivorous insects. 


\section{Introduction}

Long standing hypotheses suggest that the evolution of the tremendous diversity of insect herbivores (Gilbert 1979; Lawton 1983; Strong et al. 1984; Mitter et al. 1988; Farrell 1998; Novotny et al. 2006) relates to speciation driven by adaptation to novel host plants (Mitter et al. 1988; Schluter 2000; Dyer et al. 2007; Futuyma \& Agrawal 2009; Matsubayashi et al. 2010; Hardy \& Otto 2014). Many studies have focused on identifying the genetic basis of adaptations to novel hosts (Via 1991; Sezer \& Butlin 1998; Feder et al. 2003; Nosil 2007; Soria-Carrasco et al. 2014; Simon et al. 2015), but what factors constrain the colonization of novel hosts at first remains largely unknown (Mayhew 2007; Winkler \& Mitter 2008; Janz 2011). Indeed, multiple factors, including plant species-specific chemical compounds, which reduce insect growth and survival, are expected to hamper the ability of insect herbivores to shift to novel hosts (Scriber 1984; Hartley \& Jones 1997; War et al. 2013a, b; Portman et al. 2015).

Overcoming constraints imposed by plant chemical compounds should be especially difficult for insect species that are specialized on few related host plant species, which appears to be the case for the vast majority of herbivorous insects (e.g., Fox \& Morrow 1981; Scott 1986; Janzen 1988; Thompson 1994). Indeed, surveys of insect occurrences on plants in natural populations suggest that approximately $76 \%$ of all herbivorous insects are mono- or oligophagous, feeding on plant species belonging to a single genus or family (Forister et al. 2014). In spite of the widespread specialization, transitions from specialist to generalist habits have occurred repeatedly during the evolution of herbivorous insect clades (e.g., Funk \& Bernays 2001; Nosil \& Mooers 2005; Forister et al. 2012; Hardy \& Otto 2014), questioning the idea that adaptation to plant chemical compounds generally hampers the colonization of novel hosts. Resolving this paradox has thus far been difficult because the majority of comparative and empirical studies on herbivore specialization (including the ones mentioned above) have only focused on the number of hosts used in natural population (i.e. the realized feeding niche; Colwell \& Futuyma 1971; Futuyma \& McCafferty 1990; Nyffeler \& Sterling 1994; Blüthgen et al. 2006; Slatyer et 

factors, including insect adaptations to host plant chemistry, insect preferences (e.g., Dethier 1954; Forister et al. 2013) as well as species interactions (notably predation and competition; e.g., Hutchinson 1957; Novotny et al. 2006; Lewinsohn \& Roslin 2008; Holt 2009; Ingram et al. 2012). However, little or no information is available on the range of plants allowing for survival, growth and reproduction of herbivorous insects (i.e., the fundamental feeding niche, Whittaker et al. 1973; Leibold 1995). Thus, the evolutionary dynamics of fundamental feeding niches are elusive and it even remains unknown whether the breadths of the fundamental and realized feeding niches generally change in parallel.

We hypothesized that the ability to use different plant species as hosts and consequently the breadth of the fundamental feeding niche is influenced by the evolutionary history of an insect lineage (see also Futuyma \& McCafferty 1990). Specifically, if insect lineages can retain the ability to use their ancestral hosts as a food source after having shifted to a novel host, host shifts are expected to generate fundamental niche expansions (i.e., the lineage would become more generalist). By contrast, if insect lineages do not retain the ability to use their ancestral hosts, fundamental feeding niches will be independent of the evolutionary history of host plant use. More generally, colonization of novel host plants would be facilitated if insect lineages retained plasticity in host use present in their ancestors.

We used Timema, a small genus of herbivorous stick insects from western North America (Vickery 1993) to study the evolutionary dynamics of fundamental and realized feeding niches. Different Timema species have colonized plants from phylogenetically distant families, ranging from one to eight families of host plants per Timema species (Table 1). In terms of realized feeding niche, the Timema genus thus comprises a range of specialist to generalist species, and a tendency towards increased ecological specialization over evolutionary time was reported in a previous study (Crespi \& Sandoval 2000). The genus originated about 30 million years ago 
102

103

104

105

106

107

108

110

111

112

113

(Riesch et al. 2017), in conjunction with the origin and spread of the chaparral biome to which most species are adapted (Sandoval et al. 1998; Crespi \& Sandoval 2000). Ancestral Timema populations were most likely associated with angiosperms characterizing the chaparral biome, specifically the genera Ceanothus (lilac) and Adenostoma (chamise) (Sandoval et al. 1998; Crespi \& Sandoval 2000). Nonetheless, transitions from angiosperm to conifer hosts have occurred multiple times in the genus. Ten of the 23 known Timema species regularly use conifers from one or multiple families as hosts (Table 1). At least two conifer species (redwood, Sequoia sempervirens and white fir, Abies concolor) represent recent host shifts, as both redwood and white fir are hosts for monophyletic groups of closely related Timema species (Fig. 1).

Taking advantage of this variability in host plant use in Timema, we tested whether i) insect performance on host plants is constrained by plant phylogeny and plant chemical defenses, ii) the fundamental feeding niche breadth changes following a shift to a novel host, iii) insects retain the ability to use ancestral host plants following host shifts, and iv) fundamental and realized feeding niche sizes are correlated.

To characterize the realized feeding niches of the 23 known Timema species, we first generated a complete list of host plants for each species, using information from previous studies and field surveys. We then estimated the breadth of the fundamental feeding niche for nine of the 23 Timema species. To this end, we measured juvenile insect performance on seven phylogenetically diverse plants from the Timema host plant species pool (Table 1). This sampling strategy allowed us to study the evolutionary dynamics of specialization at the realized and fundamental niche levels. Finally, in order to explore potential mechanisms generating variable performances of insects on different plant species, we analyzed phenolic and terpenic secondary metabolites, which are toxins and/or feeding deterrents for many 
herbivorous insects (Bi \& Felton 1995; Wink 1998; Acamovic \& Brooker 2005; Dearing et al. 2005; Fürstenberg-Hägg et al. 2013).

\section{Material and Methods}

\section{Realized feeding niches}

133 In order to characterize the breadth of the realized feeding niche at the species level, we 134 established a list of the host plants for each of the 23 known Timema stick insects species from 135 the literature (Vickery 1993; Vickery \& Sandoval 1997, 1999, 2001; Crespi \& Sandoval 2000; Law \& Crespi 2002; Sandoval \& Crespi 2008; Riesch et al. 2017), and completed the list with personal observations (Table 1). We distinguished between plants for which we found evidence that Timema feed on them (hereafter "typical host plants"), and plants for which it was unclear whether they are used as a food source, or solely for resting (hereafter "putative host plants"; see Table. 1). In addition, we characterized the realized feeding niche at the population level for a subset of 22 populations from 9 species (between 1 and 6 populations per species; Table plants pool (Table. 1) were present. We then surveyed all these plants to determine the relative

144 frequency of stick insects on each plant. (Table S1).

\section{Fundamental feeding niches}

147 To measure insect performance on different hosts and their fundamental feeding niche breadths, 148 we chose seven plants known to be commonly used by several Timema species, while trying to 149 cover the phylogenetic diversity of all potential host plants (Fig. 1; Table 1). Stick insects for 150 our experiments were collected from twelve populations belonging to nine Timema species 151 throughout California (Table S1) using sweep nets. We only used fourth-instar juvenile females in order to minimize age-related effects, and to avoid the spurious effects of high mortality

153 when manipulating younger instars. Between 10 and 80 females per host plant were used to 154 measure survival and weight gain over 10 days, for a total of 70-220 females per population 
(1330 insects in total; see Fig. S1 for details on the experimental set-up). The large variation in

numbers of insects per population was generated by the natural variation in the availability of

forth instar females in different populations, as well as by the high mortality on certain plants

possible, we used more females for combinations generating high mortality.

\section{Evaluation of phylogenetic constraints regarding host use}

162 We first tested whether closely related Timema species had similar performances (survival and weight gain) on the different plants. Branches from the most recent Timema phylogeny (Riesch

167 (Mesquite module "Continuous-character Model Evaluation for phylogenetic signal testing").

168 Maximum parsimony with unordered, equal-weighted characters, and a cost of any state change

$169=1$ was used to minimize the total number of character-state changes over the tree. We then

171 to the number of changes inferred on 1000 trees for which the characters were randomized

172 across the tips in Mesquite. The null hypothesis that the character is randomly distributed on

173 the phylogeny was rejected if the observed number of state changes fell outside of the upper or

174 lower 5 percentiles of the random distribution (Maddison \& Slatkin 1991).

\section{Estimations of the degree of specialization}

177 To quantify the breadth of Timema feeding niches, we calculated the Tau specialization index

178 ( $\tau)$ (Yanai et al. 2004), as follows:

$$
\tau=\frac{\sum_{i=1}^{n}\left(1-\widehat{x_{i}}\right)}{n-1} ; \widehat{x_{i}}=\frac{x_{i}}{\max _{1 \leq i \leq n}\left(x_{i}\right)}
$$


Where $\mathbf{n}$ corresponds to the number of plants, $\mathbf{x}_{\mathbf{i}}$ represents the frequency of occurrence (for the realized niche) or the weight gain (for the fundamental niche) on plant $\mathrm{i}$, and $\mathbf{m a x}\left(\mathbf{x}_{\mathbf{i}}\right)$ is the maximum occurrence or weight gain for the focal population. The index ranges from 0 (generalist) to 1 (pure specialist). We chose this measure to estimate the degree of specialization because of its robustness to small sample sizes and because our data were quantitative and continuous (Kryuchkova-Mostacci \& Robinson-rechavi 2016). However, this index needs positive values to be calculated. We therefore transformed percentages of weight gain, which are negative when individuals lose weight, to relative weights of insects at the end of the feeding trials (i.e., an insect that lost $30 \%$ of its weight during the trial would be assigned the value 0.7 , while one that gained $30 \%$ would be assigned 1.3). To test whether broad fundamental feeding niches translate into broad realized niches at the species or population level, we correlated the

191 fundamental specialization indices Tau with the realized feeding niche breadths at the species 192 and population levels, measured respectively by the number of host plants and the Tau indices based on the frequency of different host plants used within populations. We used Phylogenetic generalized least squares (PGLS) analyses to account for phylogenetic non-independence among Timema species. These analyses were conducted using the ape (Paradis et al. 2004) and nlme (Pinheiro et al. 2009) R packages (R Core Team 2017) using a Brownian motion model 197 for trait evolution.

\section{Plant chemical profile characterization}

200 We extracted and quantified compounds in the phenolic and terpene classes of secondary 201 metabolites from leaves of the seven plant species included in our experiments (see Table 1), 202 using methods adapted from Pratt et al. (2014) and Moreira et al. (2015). For each plant species, 203 we extracted compounds from five independent replicates for both phenols and terpenes (see 204 detailed methods for plant chemical analyses in Appendix S1). 
To ordinate the chemical diversity data found across species, we conducted a principal component analysis (PCA) based on correlation matrices using the FactoMineR package in $\mathrm{R}$

208 (Husson et al. 2008). We tested whether plants have significantly different chemical compositions by estimating the chemical variation within and between species with a permutational multivariate analysis of variance (PERMANOVA) using 10.000 permutations with the adonis function (Anderson 2001) implemented in the R package vegan (Oksanen et al. 2007). We then tested for a correlation between the plant species phylogenetic distances and

213 the chemical distances across the seven species tested using Mantel-tests with 10’000 214 permutations.

216 Finally, for the subset of chemical compounds that are present in multiple plants, we evaluated 217 whether insect performances were negatively (or positively) correlated with the amount of a 218 given compound. We conducted Spearman correlation tests (separately for each Timema 219 population) between insect weight gain and each of the chemical compounds. These tests 220 provided us for each Timema species with a list of chemical compounds significantly correlated 221 to insect performance. We then tested whether these lists were more similar between different 222 Timema populations than expected by chance, using hypergeometric tests with the phyper 223 function in R (Johnson et al. 2005). Thus, we were not interested in the specific lists of 224 significant chemical compounds per Timema population (which comprise many false positives 225 due to multiple testing), but we were interested to see if the same compounds affect the 226 performance of multiple Timema populations.

\section{Results}

Insect performances on different plants

231 The performance (survival and weight gain during 10 days) of Timema individuals was strongly 232 dependent on the plant species tested. For ten of the twelve Timema populations, both survival 
and weight gain varied significantly among individuals reared on different plant species, while

234 for the two remaining populations, only weight gain varied significantly (Table S2, Fig. S2).

235 Insect survival and weight gain were also significantly correlated (Spearman rank correlation,

$236 \mathrm{r}=0.66, \mathrm{p}<0.0001$ ), even though the most extreme situation (i.e., when all Timema of a given

237 population died on a specific host plant before 10 days) could not be included in the analysis.

Generally, we found that insect performance was not maximal on the host plant they were

240 collected on (henceforth referred to as the native host plant) (Table S2, Fig. S2). Indeed, for

241 only five out of the 12 populations, individuals survived best on their native host plant, while

242 for only six out of 12 populations they gained the most weight. In some cases, the performance

243 of insects increased dramatically when individuals were reared on plant species they never use

244 as host in the field. For example, $100 \%$ of $T$. bartmani survived for 10 days on lilac, while only

$24535.4 \%$ of them survived on their native host plant, white fir (Table S2).

247 We also observed that some host plant species are a consistently better food source than others.

248 For instance, lilac was almost always the best food source, even for Timema species that never 249 use lilac in natural conditions. Specifically, relative survival on lilac was high for all populations 250 (between $76.9 \%$ and $100 \%$, Table S2), and individuals from nine of the twelve Timema 251 populations gained more weight when reared on lilac than when reared on any other plant 252 species (Fig. S2). Lilac is the native host for only three of these nine populations (T. cristinae253 lil, T. knulli-lil and T. petita), the six remaining ones were collected on manzanita $(T$. 254 californicum-mz), chamise (T. cristinae-cha), oak (T. californicum-oak), mountain mahogany 255 (T. boharti and T. chumash) or redwood (T. knulli-rdw). Only T. podura, T. poppensis and T. 256 bartmani individuals had the highest weight gain when fed with their native host plant, with 257 lilac ranking second. 
Redwood was on the opposite end of the host plant quality spectrum, as it was only exploitable by Timema individuals originally collected on it. Relative survival on redwood for individuals

261 from the two native redwood populations was high (75.0 and 86.7\% for T. poppensis and T. knulli-rdw respectively; Table S2), while survival was low for all other Timema populations

263 (ranging from 0\% to 55.6\%; Table S2). Similarly, T. poppensis and T. knulli-rdw were the only 264 species that gained significant weight when fed with redwood for ten days (mean weight gain was $45.3 \%$ and $67.7 \%$ for the two species, respectively; Fig. S2). For the ten other populations,

266 if individuals are able to survive for ten days on redwood, they typically lost weight (80\% of surviving individuals) or only gained very little (20\% of surviving individuals gained weight, with a maximum gain of 9.9\%; Fig. S2). For the T. bartmani, T. boharti, T. podura, and T. cristinae-cha populations, not a single individual survived for ten days on redwood.

We observed the same pattern for T. knulli, the only Timema species using both redwood and lilac under natural conditions (Table 1). All individuals collected on redwood were able to live and grow on all tested plants (Table S2, Fig. S2). By contrast, practically all individuals of the same species collected on lilac died or lost significant weight on redwood (Table S2, Fig. S2).

\section{Degree of fundamental and realized specialization}

277 The fundamental and realized feeding niche breadths were not correlated, neither at the species 278 level, nor at the population level. At the species level, we found no significant correlation when 279 considering the total number of host plant genera per Timema species (correlation corrected 280 with Phylogenetic Generalized Least Squares (PGLS); $\mathrm{r}=-0.41, \mathrm{p}=0.43$; Fig. 2), or when 281 considering only the typical plant genera (PGLS; $\mathrm{r}=-0.17, \mathrm{p}=0.75)$ ). The lack of correlation is 282 unlikely caused by a lack of power as the general pattern is suggestive of a negative correlation 283 between realized and fundamental niches rather than the expected positive correlation (Fig. 2).

284 At the population level, we also found no correlation between Tau indices estimating the 
fundamental feeding niche and Tau indices estimating the realized niche (Pearson correlation test, $\mathrm{r}=0.02, \mathrm{p}=0.91)$.

The fundamental specialization indices showed that the two Timema species from redwood significantly more generalist $(\mathrm{Tau}=0.23,95 \% \mathrm{CI} 0.19-0.30)$ than the population of the same species collected on lilac $(\mathrm{Tau}=0.44,95 \% \mathrm{CI} 0.34-0.50)$. Hence, Timema native to redwood had a broader potential feeding niche than populations living on other host plants. In order to verify that this tendency was not only generated by the performance of the insects on redwood, we recalculated the Tau indices across six plants, excluding data from redwood. T. poppensis.

T. knulli-rdw remained the most generalist species when the Tau indices were calculated without data from redwood (Fig. S5), and the Tau indices with and without redwood were strongly correlated (Pearson correlation; $\mathrm{r}: 0.96, \mathrm{p}<0.0001$ ), indicating that the pattern was not solely driven by redwood.

These results suggest that the fundamental feeding niches of T. poppensis and T. knulli-rdw have expanded as a result of adaptation to redwood. To corroborate these findings, we reared individuals from three Timema species (T. poppensis, T. californicum-oak and T. podura) on plants not used as hosts by natural Timema populations (Rhus ovata (sugar sumac), Baccharis pilularis (coyote bush) and Artemisia californica (sage bush)). Again, T. poppensis native to redwood performed better on these novel host plants than the two other insect species (Fig. 3B).

Effect of plant chemical composition on Timema performances

308 To explore potential mechanisms generating variation in food quality among host plants, we studied the phenolic and terpenic secondary metabolites. We found a total of 521 different chemical compounds (28 phenols and 493 terpenes) across the seven plant species tested, with 
$<0.001)$. In addition to chemical diversity, we also found that the total volume of compounds varied widely among plant species (volume measured as $\mu \mathrm{g}$ Gallic Acid Equivalent /g Dry

314 Matter; average: $564 \mu \mathrm{g} / \mathrm{g}$; range 298 -1192), with a smaller volume in angiosperms (average: $310 \mu \mathrm{g} / \mathrm{g}$; range 298 - 331) than conifers (average: $902 \mu \mathrm{g} / \mathrm{g}$; range 650 - 1192; Welch Two Sample t-test; $\left.\mathrm{t}_{2}=-3.75 ; \mathrm{p}=0.063\right)$.

The PCA differentiated four plant groups, containing: 1) lilac, 2) oak, chamise, and manzanita, 3) redwood and douglas fir, and 4) white fir (Fig. S6). Distances between terpenic compositions of plants were correlated with the between plant phylogenetic distances (Mantel-test with 10.000 permutations, $\mathrm{r}=0.77, \mathrm{p}=0.014$ ), while there was no significant correlation for the phenolic compositions (Mantel-test with 10.000 permutations, $r=-0.04, p=0.47$ ).

Most of the isolated terpenic and phenolic compounds were specific to a single plant or a subset of plants (Fig. S7). Specifically, $45.9 \%$ of the 521 compounds were detected only in a single plant, and only $1.5 \%$ of the compounds occurred in all seven plant species (Fig. S7). To test whether the performances of multiple Timema species were related to similar plant chemistries, we used the 162 compounds (31\%) that occurred in at least three plant species. Among these, 84 (65 after FDR $=0.05$ correction) were significantly correlated to insect weight gain in at least one Timema population. No single compound was found to be significantly correlated with

331 the performance of Timema individuals collected from both angiosperms and conifers (Fig. 4). By contrast, 26 compounds (30.5\%) were significantly correlated to the weight gain of insects from six of the nine populations living on angiosperms. One additional compound was further 334 correlated to the weight gain of individuals of both populations collected from redwood ( $T$. poppensis and T. knulli-rdw; Fig. 4). As phenols and terpenes are known to play an important role in plant defense against herbivorous insects, these compounds were expected to negatively affect insect performances. However, 59.2\% of the compounds showed a positive effect ( $\mathrm{r}$ varying between 0.77 and 0.99; Fig. 4), suggesting that some phenolic and terpenic compounds 
may favor rather than constrain Timema performance. The number of compounds significantly

correlated to insect performance and shared among several populations significantly exceeded

341 the amount of sharing expected by chance (Hypergeometric tests, p varying between 1e-06 and 342 1e-18).

\section{Discussion}

346 By studying the evolutionary dynamics of realized and fundamental feeding niches of multiple insect herbivores species in a phylogenetic framework, we developed novel insights into the mechanisms underlying feeding niche contractions and expansions. We analyzed the

349 fundamental and realized feeding niches of Timema stick insects, which comprise a range of 350 ecologically specialist to generalist species. We showed that insects expanded their 351 fundamental feeding niches after shifting to new hosts. These fundamental niche size expansions occurred via two mechanisms. First, the species that shifted to novel hosts retained

353 the ability to use plant groups used by their ancestors, even though the latest host shifts in

354 Timema occurred 3-12 million years ago (Fig. 1). Second, adaptation to particularly toxic hosts 355 (i.e., redwood) allows insects to metabolize chemically diverse plants, including plants 356 currently not used as hosts by any species of the Timema genus. In combination, these 357 mechanisms can explain how generalist insect herbivores (as measured from the realized 358 feeding niche) can evolve from specialists, a pattern detected repeatedly at the 359 macroevolutionary scale (Schluter 2000; Janz et al. 2001, 2006; Nosil \& Mooers 2005; 360 Stireman 2005; Winkler \& Mitter 2008). Furthermore, fundamental feeding niche expansions 361 following host shifts should facilitate future host shifts in the same lineage, which could 362 generate frequent host turnovers via positive feedback loops of host adaptation and range 363 expansion. 
While several ecological factors, such as competition, predation or limited dispersal (e.g.,

Futuyma \& Moreno 1988; Agosta 2006; Agosta \& Klemens 2008) can drive ecological

specialization, plant secondary chemistry has been brought forward as a key component driving insect performance and host plant specialization for herbivorous insects (e.g., Ehrlich \& Raven

1964; Bi \& Felton 1995; Dearing et al. 2005; Rosenthal \& Berenbaum 2012; Portman et al.

2015). In the present study however, adaptation to a particular host plant chemistry does not

explain ecological specialization in Timema. Indeed, the performance of Timema individuals

was typically not maximized on their native host plant, as previously shown in feeding

experiments with chamise and lilac for insect populations adapted to these two plants (e.g., terpenic compounds on insect performance.

Although we did not investigate the mechanisms driving host specialization in Timema, previous work in one species (T. cristinae) has shown that predation and plant preference (independently of plant quality) are key factors determining the distribution of insects on potential hosts (Sandoval 1994; Nosil et al. 2003; Sandoval \& Nosil 2005). There is also accumulating evidence from herbivorous insects in general that preferences for host plant species are often not linked to the quality of plants as a food source, suggesting that insect 388 preferences evolve more rapidly than insect physiologies (e.g., Rausher 1979; Thompson 1988; 389 Valladares \& Lawton 1991; Underwood 1994; Fritz et al. 2000; Faria \& Fernandes 2001; 390 Keeler \& Chew 2008). Such preference-driven host plant selection in natural populations could 391 help explain the lack of correlation between realized and fundamental niche size in Timema. 
Independently of the specific mechanisms driving host plant specialization in Timema, our results indicate that insect herbivores are more constrained by the biotic pressures of their environment than by their intrinsic physiological ability to metabolize particular plant species.

In the case of redwood, host plant chemistry might however indirectly mediate host plant use by relaxing insect-insect competition or pathogen pressure. Redwood is a host for only few herbivore species (Furniss 1977; Su \& Tamashiro 1986; Grace \& Yamamoto 1994), suggesting that competition on this host plant is low. In addition, laboratory experiments have shown that its wood inhibits the growth of bacteria (Scheffer 1966; Taha \& Shakour 2016), and fungi

401 (Shrimpton \& Whitney 1968; Espinosa-Garcia \& Langenheim 1990; Espinosa-Garcia et al. 1991), which may reduce pathogen pressure for insects. Finally, fires, being very common and an essential component of the Californian ecosystems (Minnich 1983; Brooks et al. 2004;

404 Clinton et al. 2006), can favor redwood-insect associations. Thanks to their thick bark, 405 redwoods can easily withstand high levels of burning (Jacobs et al. 1985; Ramage et al. 2010).

Timema on redwood may thus survive fires while they would perish on more profitable hosts such as lilac or chamise. Using redwood may thus be overall beneficial even if it represents a non-optimal food source.

Our results suggest that the specific ability to use redwood is a key feeding innovation that allowed for range expansions in species that shifted to this host. Our feeding experiments showed that redwood is toxic to all Timema populations except for the native ones, while 413 populations collected on redwood were able to survive and grow on all other tested host plants. 414 Only three Timema species are known to use redwood in nature: T. poppensis and T. knulli 415 (used in the present study), and T. douglasi, an asexual species very closely related to $T$. poppensis (Table 1). According to the most recent Timema phylogeny (Riesch et al. 2017), the

417 last common ancestor of these three species occurred approximately 6.8 million years ago (Fig. 418 1), suggesting that the colonization of redwood happened around that time. The Timema genus 
(Sandoval et al. 1998; Law \& Crespi 2002), with several range expansion events for the species currently occurring at the northern end of the distribution such as T. poppensis and T. douglasi (the exact distribution of T. knulli is not known). Therefore, the incorporation of redwood in their diet was very likely of paramount importance for these herbivores to be able to expand their range northward. Indeed, the geographic distribution of redwood spreads over $750 \mathrm{~km}$ along the Pacific coast of the United States (Farjon 2005), while reaching further north than most other Timema host plants.

In conclusion, our study provides new insights into the consequences of host shifts for the breadth of the fundamental feeding niche. These consequences are highly relevant as they influence the probability for additional host shifts and potential host-associated diversification. Specifically, we showed that the ability to use ancestral hosts is maintained following major host shifts for at least 10 million years (as when moving from angiosperms to conifers), and that adaptations to chemically challenging hosts are not necessarily associated with decreased performance on alternative hosts. To the contrary, we here showed that adaptations to chemically challenging hosts allowed insects to metabolize a broad range of phylogenetically unrelated plants, including plants that have never been used as hosts in natural populations.

437 More generally, the joint analysis of fundamental and realized feeding niches in multiple related insect species provides unique insights into the mechanisms driving the evolutionary dynamics of host range expansions and contractions in herbivorous insects.

\section{Acknowledgments}

442 We thank Kirsten Jalvingh, Armand Yazdani and Bart Zijlstra for help in the field, Loren Bes 443 (www.lorenbes.com) for the plant illustrations and Frédéric Bastian and Elsa Guillot for useful 444 discussions regarding data analysis. We thank Jessica Purcell at UC Riverside for labspace and 445 Darren Parker for proofreading. This study was supported by grant PP00P3 139013 of the Swiss 446 FNS to TS and a fieldwork grant from the Swiss Zoological Society to CL. 
Acamovic, T. \& Brooker, J.D. (2005). Biochemistry of plant secondary metabolites and their effects in animals. Proc. Nutr. Soc., 64, 403-412.

Agosta, S.J. (2006). On ecological fitting, plant-insect associations, herbivore host shifts, and host plant selection. Oikos, 114, 556-565.

Agosta, S.J. \& Klemens, J.A. (2008). Ecological fitting by phenotypically flexible genotypes: Implications for species associations, community assembly and evolution. Ecol. Lett., 11, $1123-1134$.

Anderson, M.J. (2001). A new method for non parametric multivariate analysis of variance. Austral Ecol., 26, 32-46.

Bi, J.L. \& Felton, G.W. (1995). Foliar oxidative stress and insect herbivory: Primary compounds, secondary metabolites, and reactive oxygen species as components of induced resistance. J. Chem. Ecol., 21, 1511-1530.

Blüthgen, N., Menzel, F. \& Blüthgen, N. (2006). Measuring specialization in species interaction networks. BMC Ecol., 6, 9.

Brooks, M.L., D’Antonio, C.M., Richardson, D.M., Grace, J.B., Keeley, J.E., DiTomaso, J.M., et al. (2004). Effects of invasive alien plants on fire regimes. Bioscience, 54, 677-688.

Clinton, N.E., Gong, P. \& Scott, K. (2006). Quantification of pollutants emitted from very large wildland fires in Southern California, USA. Atmos. Environ., 40, 3686-3695.

Colwell, R.K. \& Futuyma, D.J. (1971). On the measurement of niche breadth and overlap. Ecology, 52, 567-576.

Crespi, B.J. \& Sandoval, C.P. (2000). Phylogenetic evidence for the evolution of ecological specialization in Timema walking-sticks. J. Evol. Biol., 13, 249-262.

Dearing, M.D., Foley, W.J. \& McLean, S. (2005). The influence of plant secondary metabolites on the nutritional ecology of herbivorous terrestrial vertebrates. Annu. Rev. Ecol. Evol. Syst., 36, 169-189.

Dethier, V.G. (1954). Evolution of feeding preferences in phytophagous insects. Evolution., 8, 33-54.

Dyer, L.A., Singer, M.S., Lill, J.T., Stireman, J.O., Gentry, G.L., Marquis, R.J., et al. (2007). Host specificity of Lepidoptera in tropical and temperate forests. Nature, 448, 696-699.

Ehrlich, P.R. \& Raven, P.H. (1964). Butterflies and plants : A study in coevolution. Soc. Study Evol., 18, 586-608.

Espinosa-Garcia, F.J. \& Langenheim, J.H. (1990). The endophytic fungal community in leaves of a coastal redwood population - Diversity and spatial patterns. Source New Phytol., 116, 89-97.

Espinosa-Garcia, F.J., Langenheimt, J.H. \& Langenheim, J.H. (1991). Effect of some leaf essential oil phenotypes in coastal redwood on the growth of several fungi with endophytic stages. Biochem. Syst. Ecol., 19, 629-642.

Faria, M.L. \& Fernandes, W.G. (2001). Vigour of a dioecious shruband attack by a galling herbivore. Ecol. Entomol., 26, 37-45.

Farjon, A. (2005). A monograph of Cupressaceae and Sciadopitys. Kew: Royal Botanic Gardens.

Farrell, B.D. (1998). "Inordinate fondness" explained: Why are there so many beetles? Science., 281, 555-559.

Feder, J.L., Berlocher, S.H., Roethele, J.B., Dambroski, H., Smith, J.J., Perry, W.L., et al. (2003). Allopatric genetic origins for sympatric host-plant shifts and race formation in Rhagoletis. Proc. Natl. Acad. Sci. USA, 100, 10314-10319.

Fordyce, J.A., Nice, C.C., Hamm, C.A. \& Forister, M.L. (2016). Quantifying diet breadth through ordination of host association. Ecology, 97, 842-849.

Forister, M.L., Dyer, L. a, Singer, M.S., Stireman, J.O. \& Lill, J.T. (2012). Revisiting the evolution of ecological specialization, with emphasis on insect-plant interactions. Ecology, 93, 981-991. 
Forister, M.L., Novotny, V., Panorska, A.K., Baje, L., Basset, Y., Butterill, P.T., et al. (2014). The global distribution of diet breadth in insect herbivores. Proc. Natl. Acad. Sci. USA, $112,442-447$.

Forister, M.L., Scholl, C.F., Jahner, J.P., Wilson, J.S., Fordyce, J.A., Gompert, Z., et al. (2013). Specificity, rank preference, and the colonization of a non-native host plant by the Melissa blue butterfly. Oecologia, 172, 177-188.

Fox, L.R. \& Morrow, P.A. (1981). Specialization: species property or local phenomenon? Science., 211, 887-893.

Fritz, R.S., Crabb, B.A. \& Hochwender, C.G. (2000). Preference and performance of a gallinducing sawfly: A test of the plant vigor hypothesis. Oikos, 89, 555-563.

Funk, D.J. \& Bernays, E. a. (2001). Geographic variation in host specificity reveals host range. Ecology, 82, 726-739.

Furniss, R.L. (1977). Western forest insects. US Department of Agriculture, Forest Service.

Fürstenberg-Hägg, J., Zagrobelny, M. \& Bak, S. (2013). Plant defense against insect herbivores. Int. J. Mol. Sci., 14, 10242-10297.

Futuyma, D.J. \& Agrawal, A.A. (2009). Evolutionary history and species interactions. Proc. Natl. Acad. Sci. USA, 106, 18043-18044.

Futuyma, D.J. \& McCafferty, S.S. (1990). Phylogeny and the evolution of host plant associations in the leaf beetle genus Ophraella (Coleoptera, Chrysomelidae). Evolution., 44, 1885-1913.

Futuyma, D.J. \& Moreno, G. (1988). The evolution of ecological specialization. Annu. Rev. Ecol. Syst., 19, 207-233.

Gilbert, L.E. (1979). Development of theory in the analysis of insect-plant interactions. Anal. Ecol. Syst., 3, 117.

Grace, J.K. \& Yamamoto, R.T. (1994). Natural resistance of Alaska-cedar, redwood, and teak to Formosan subterranean termites. For. Prod. J., 44, 41-45.

Hardy, N.B. \& Otto, S.P. (2014). Specialization and generalization in the diversification of phytophagous insects: Tests of the musical chairs and oscillation hypotheses. Proc. R. Soc. B Biol. Sci., 281.

Hartley, S.E. \& Jones, C.G. (1997). Plant chemistry and herbivory, or why the world is green. In: Plant Ecology (ed. Crawley, M.J.). Blackwell Science, Oxford, pp. 284-324.

Hedges, S.B., Marin, J., Suleski, M., Paymer, M. \& Kumar, S. (2015). Tree of life reveals clocklike speciation and diversification. Mol. Biol. Evol., 32, 835-845.

Holt, R.D. (2009). Bringing the Hutchinsonian niche into the 21st century: ecological and evolutionary perspectives. Proc. Natl. Acad. Sci., 106, 19659-19665.

Husson, F.F., Lê, S., Josse, J. \& Husson, F.F. (2008). FactoMineR: An R Package for Multivariate Analysis. J. Stat. Softw., 25, 1-18.

Hutchinson, G.E. (1957). Concluding remarks. Cold Spring Harbor Symposium on Quantitative Biology.

Ingram, T., Svanbäck, R., Kraft, N.J.B., Kratina, P., Southcott, L. \& Schluter, D. (2012). Intraguild predation drives evolutionary niche shift in threespine stickleback. Evolution., 66, 1819-1832.

Jacobs, D.F., Cole, D.W. \& McBride, J.R. (1985). Fire history and perpetuation of natural coast redwood ecosystems. J. For., 83, 494-497.

Janz, N. (2011). Ehrlich and Raven revisited: Mechanisms underlying codiversification of plants and enemies. Annu. Rev. Ecol. Evol. Syst., 42, 71-89.

Janz, N., Nyblom, K. \& Nylin, S. (2001). Evolutionary dynamics of host-plant specialization: A case study of the tribe Nymphalini. Evolution., 55, 783-796.

Janz, N., Nylin, S. \& Wahlberg, N. (2006). Diversity begets diversity: host expansions and the diversification of plant-feeding insects. BMC Evol. Biol., 6, 4.

Janzen, D.H. (1988). Ecological characterization of a Costa Rican dry forest caterpillar fauna. Biotropica, 20, 120-135.

Johnson, N.L., Kemp, A.W. \& Kotz, S. (2005). Univariate discrete distributions. John Wiley 
\& Sons, Chichester.

Keeler, M.S. \& Chew, F.S. (2008). Escaping an evolutionary trap: Preference and performance of a native insect on an exotic invasive host. Oecologia.

Kryuchkova-Mostacci, N. \& Robinson-rechavi, M. (2016). A benchmark of gene expression tissue-specificity metrics. Brief. Bioinform., 18, 205-214.

Kumar, S., Stecher, G., Suleski, M. \& Hedges, S.B. (2017). TimeTree: A resource for timelines, timetrees, and divergence times. Mol. Biol. Evol., 34, 1812-1819.

Law, J.H. \& Crespi, B.J. (2002). The evolution of geographic parthenogenesis in Timema walking-sticks. Mol. Ecol., 11, 1471-1489.

Lawton, J.H. (1983). Plant architecture and the diversity of phytophagous insects. Annu. Rev. Entomol., 28, 23-39.

Lewinsohn, T.M. \& Roslin, T. (2008). Four ways towards tropical herbivore megadiversity. Ecol. Lett., 11, 398-416.

Maddison, W.P. \& Maddison, D.R. (2017). Mesquite: A modular system for evolutionary analysis.

Maddison, W.P. \& Slatkin, M. (1991). Null models for the number of evolutionary steps in a character on a phylogenetic tree. Evolution., 45, 1184-1197.

Matsubayashi, K.W., Ohshima, I. \& Nosil, P. (2010). Ecological speciation in phytophagous insects. Entomol. Exp. Appl., 134, 1-27.

Mayhew, P.J. (2007). Why are there so many insect species? Perspectives from fossils and phylogenies. Biol. Rev., 82, 425-454.

Minnich, R.A. (1983). Fire mosaics in southern California and northern Baja California. Science., 219, 1287-1294.

Mitter, C., Farrell, B. \& Wiegmann, B. (1988). The phylogenetic study of adaptive zones: Has phytophagy promoted insect diversification? Am. Nat., 132, 107-128.

Moreira, X., Abdala-Roberts, L., Hernández-Cumplido, J., Rasmann, S., Kenyon, S.G. \& Benrey, B. (2015). Plant species variation in bottom-up effects across three trophic levels: A test of traits and mechanisms. Ecol. Entomol., 40, 676-686.

Nosil, P. (2007). Divergent host plant adaptation and reproductive isolation between ecotypes of Timema cristinae walking sticks. Am. Nat., 169, 151-162.

Nosil, P., Crespi, B.J. \& Sandoval, C.P. (2003). Reproductive isolation driven by the combined effects of ecological adaptation and reinforcement. Proc. Biol. Sci., 270, 1911-1918.

Nosil, P. \& Mooers, A.Ø. (2005). Testing Hypotheses About Ecological Specialization Using Phylogenetic Trees. Evolution., 59, 2256-2263.

Novotny, V., Drozd, P., Miller, S.E., Kulfan, M., Janda, M., Basset, Y., et al. (2006). Why are there so many species of herbivorous insects in tropical rainforests? Science., 313, 11151118.

Nyffeler, M. \& Sterling, W.L. (1994). Comparison of the feeding niche of polyphagous insectivores (Araneae) in a Texas cotton plantation: Estimates of niche breadth and overlap. Environ. Entomol., 23, 1294-1303.

Oksanen, J., Kindt, R., Legendre, P., O’Hara, R.B., Stevens, H.H. \& Suggests, S. (2007). The Vegan package. Community Ecol. Packag., 10, 631-637.

Paradis, E., Claude, J. \& Strimmer, K. (2004). APE: Analyses of phylogenetics and evolution in R language. Bioinformatics, 20, 289-290.

Pinheiro, J.D.B., DebRoy, S. \& Sarkar, D. (2009). nlme: Linear and nonlinear mixed effects models. R Packag. version 3, 96.

Portman, S.L., Kariyat, R.R., Johnston, M.A., Stephenson, A.G. \& Marden, J.H. (2015). Inbreeding compromises host plant defense gene expression and improves herbivore survival. Plant Signal. Behav., 10, e998548.

Pratt, J.D., Keefover-Ring, K., Liu, L.Y. \& Mooney, K.A. (2014). Genetically based latitudinal variation in Artemisia california secondary chemistry. Oikos, 123, 953-963.

R Core Team. (2017). R: A language and environment for statistical computing. R foundation for statistical computing, Vienna, Austria. 
Ramage, B.S., O'Hara, K.L. \& Caldwell, B.T. (2010). The role of fire in the competitive dynamics of coast redwood forests. Ecosphere, 1, 1-18.

Rasmann, S., Alvarez, N. \& Pellissier, L. (2014). The altitudinal niche-breadth hypothesis in insect-plant interactions. In: Annual Plant Reviews (eds. Voelckel, C. \& Jander, G.). John Wiley \& Sons, Chichester, pp. 339-359.

Rausher, M.D. (1979). Larval habitat suitability and oviposition preference in three related butterflies. Ecology, 60, 503-511.

Riesch, R., Muschick, M., Lindtke, D., Villoutreix, R., Comeault, A.A., Farkas, T.E., et al. (2017). Transitions between phases of genomic differentiation during stick-insect speciation. Nat. Ecol. Evol., 1, 1-13.

Rosenthal, G.A. \& Berenbaum, M R. (2012). Herbivores: their interactions with secondary plant metabolites: ecological and evolutionary processes. Academic Press.

Sandoval, C., Carmean, D.A. \& Crespi, B.J. (1998). Molecular phylogenetics of sexual and parthenogenetic Timema walking-sticks. Proc. R. Soc. B Biol. Sci., 265, 589-595.

Sandoval, C.P. (1994). Differential visual predation on morphs of Timema cristinae (Phasmatodeae: Timemidae) and its consequences for host-range. Biol. J. Linn. Soc., 52, 341-356.

Sandoval, C.P. \& Crespi, B.J. (2008). Adaptive evolution of cryptic coloration: The shape of host plants and dorsal stripes in Timema walking-sticks. Biol. J. Linn. Soc., 94, 1-5.

Sandoval, C.P. \& Nosil, P. (2005). Counteracting selective regimes and host preference evolution in ecotypes of two species of walking-sticks. Evolution., 59, 2405-2413.

Scheffer, T.C. (1966). Natural resistance of wood to microbial deterioration. Annu. Rev. Phytopathol., 4, 147-168.

Schluter, D. (2000). The ecology of adaptive radiations. Oxford Ser. Oxford University Press, Oxford.

Scott, J.A. (1986). The butterflies of North America. Stanford Univ. Press, Stanford, CA.

Scriber, J.M. (1984). Host-plant suitability. In: Chemical ecology of insects (eds. Bell, W. \& Cardé, R.T.). Chapman and Hall, London, pp. 159-202.

Sezer, M. \& Butlin, R.K. (1998). The genetic basis of oviposition preference differences between sympatric host races of the brown planthopper (Nilaparvata lugens). Proc. R. Soc. B-Biological Sci., 265, 2399-2405.

Shannon, P., Markiel, A., Ozier, O., Baliga, N.S., Wang, J.T., Ramage, D., et al. (2003). Cytoscape: A software environment for integrated models of biomolecular interaction networks. Genome Res., 13, 2498-2504.

Shrimpton, D.M. \& Whitney, H.S. (1968). Inhibition of growth of blue stain fungi by wood extractives. Can. J. Bot., 46, 757-761.

Simon, J.C., D’alençon, E., Guy, E., Jacquin-Joly, E., Jaquiéry, J., Nouhaud, P., et al. (2015). Genomics of adaptation to host-plants in herbivorous insects. Brief. Funct. Genomics, 14, 413-423.

Slatyer, R.A., Hirst, M. \& Sexton, J.P. (2013). Niche breadth predicts geographical range size: A general ecological pattern. Ecol. Lett., 16, 1104-1114.

Soria-Carrasco, V., Gompert, Z., Comeault, A.A., Parkas, T.E., Parchman, T.L., Johnston, J.S., et al. (2014). Stick insect genomes reveal natural selection's role in parallel speciation. Science., 344, 738-742.

Stireman, J.O. (2005). The evolution of generalization? Parasitoid flies and the perils of inferring host range evolution from phylogenies. J. Evol. Biol., 18, 325-336.

Strong, D.R., Lawton, J.H. \& Southwood, S.R. (1984). Insects on plants: Community patterns and mechanisms. Blackwell Scientific Publicatons, Oxford.

Su, N.-Y. \& Tamashiro, M. (1986). Wood-consumption rate and survival of the formosan subterranean termite (Isoptera: Rhinotermitidae) when fed one of six woods used commercially in Hawaii. Proceedings, Hawaiian Entomol. Soc., 26, 109-113.

Taha, K.F. \& Shakour, Z.T.A. (2016). Chemical Composition and Antibacterial Activity of Volatile Oil of Sequoia sempervirens (Lamb.) Grown in Egypt. Med. Aromat. plants, 5. 
Thompson, J.N. (1988). Evolutionary ecology of the relationship between oviposition preference and performance of off spring in phytophagons insects. Entomol. exp. appl., 47, 3-14.

Thompson, J.N. (1994). The coevolutionary process. University of Chicago Press, Chicago.

Underwood, D.L.A. (1994). Intraspecific variability in host plant quality and ovipositionaI preferences in Eucheira socialis (Lepidoptera: Pieridae). Ecol. Entomol., 19, 245-256.

Valladares, G. \& Lawton, J.H. (1991). Host-plant selection in the holly leaf-miner: Does mother know best? J. Anim. Ecol., 60, 227-240.

Via, S. (1991). The genetic structure of host plant adaptation in a spatial patchwork: demographic variability among reciprocally transplanted pea aphid clones. Evolution., 45, 827-852.

Vickery, V.R. (1993). Revision of Timema Scudder (Phasmatoptera: Timematodea) including three new species. Can. Entomol., 125, 657-692.

Vickery, V.R. \& Sandoval, C.P. (1997). Timema bartmani (Phasmatoptera: Timematodea: Timematidae), a new species from southern California. Can. Entomol., 129, 933-936.

Vickery, V.R. \& Sandoval, C.P. (1999). Two new species of Timema (Phasmoptera: Timematodea: Timematidae), one parthenogenetic, in California. J. Orthoptera Res., 8, 41-43.

Vickery, V.R. \& Sandoval, C.P. (2001). Descriptions of three new species of Timema (Phasmatoptera: Timematodea: Timematidae) and notes on three other species. $J$. Orthoptera Res., 10, 53-61.

War, A.R., Paulraj, M.G., Hussain, B., Buhroo, A.A., Ignacimuthu, S. \& Sharma, H.C. (2013a). Effect of plant secondary metabolites on legume pod borer, Helicoverpa armigera. J. Pest Sci. (2004)., 86, 399-408.

War, A.R., Paulraj, M.G., Ignacimuthu, S. \& Sharma, H.C. (2013b). Defensive responses in groundnut against chewing and sap-sucking insects. J. Plant Growth Regul., 32, 259-272.

Wink, M. (1998). Chemical ecology of alkaloids. Alkaloids, 265-300.

Winkler, I.S. \& Mitter, C. (2008). The phylogenetic dimension of insect-plant interactions: A review of recent evidence. Spec. Speciation, Radiat. Evol. Biol. Herbiv. Insects, 240-263.

Yanai, I., Benjamin, H., Shmoish, M., Chalifa-Caspi, V., Shklar, M., Ophir, R., et al. (2004). Genome-wide midrange transcription profiles reveal expression level relationships in human tissue specification. Bioinformatics, 21, 650-659. 
Table 1. Timema species and their recorded host plants in the wild. Plants labeled with an " $\mathrm{X}$ " correspond to a common host for a given Timema species, where experimental evidence confirms that the plant is used as a food source. Plants labeled with "." correspond to rare/anecdotal observations where it is unclear whether these plants are used as a food source (or solely for resting). Columns highlighted in gray indicate the Timema species used in the present study, sampling locations are specified in Table S1. Plants used for feeding experiments are written in bold. The plants on which the corresponding Timema populations were collected for this study are encircled. Note two of the Timema species are undescribed: Timema 'Limberpine', mentioned first by Sandoval \& Crespi (2008), and Timema 'Cuesta ridge' from Riesch et al. (2017). The phylogenetic distances between the plant genera are estimated with information from the public database TIMETREE (http://timetree.org/; Hedges et al. 2015; Kumar et al. 2017).

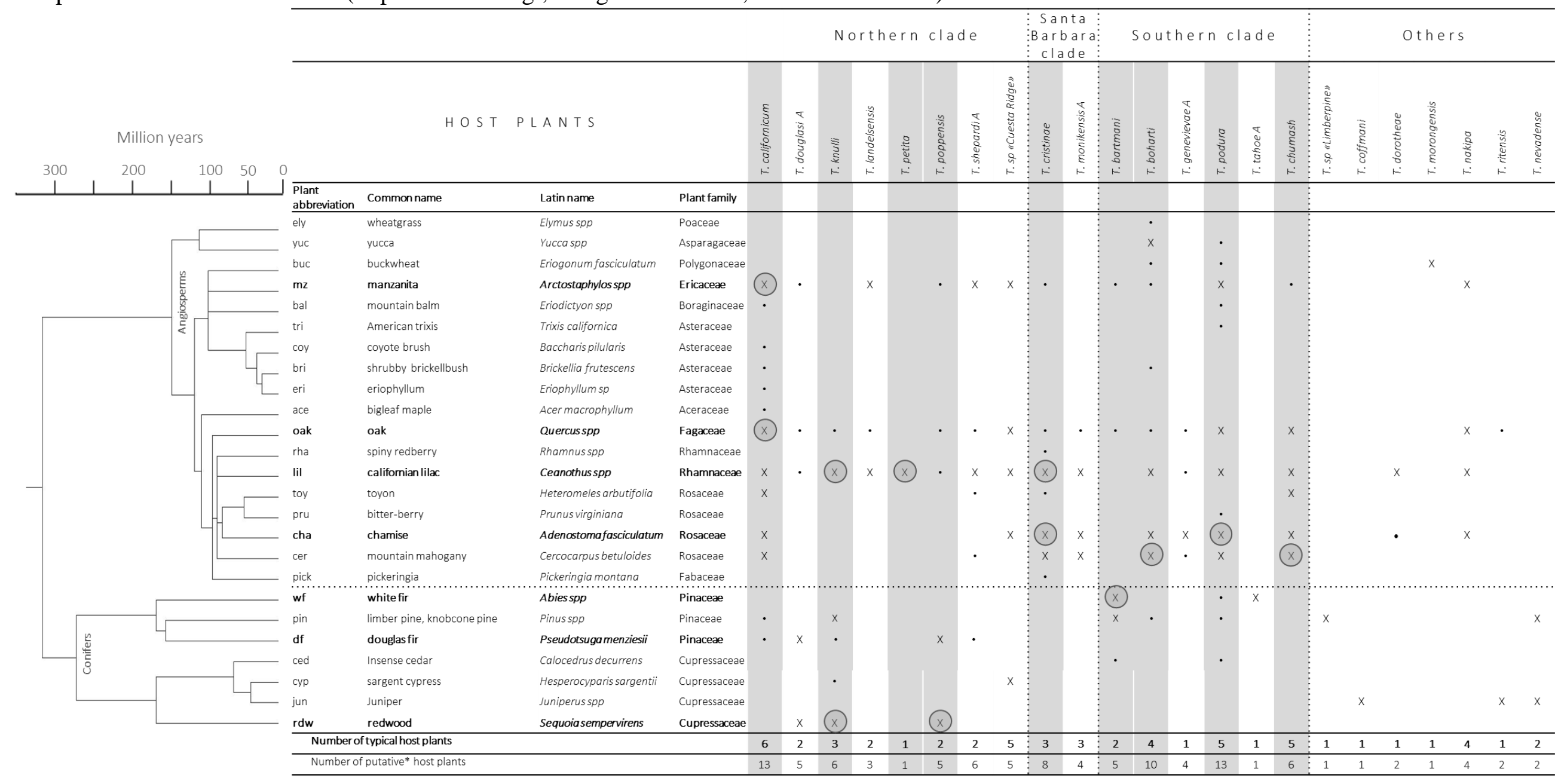




\section{Figures}

2

3

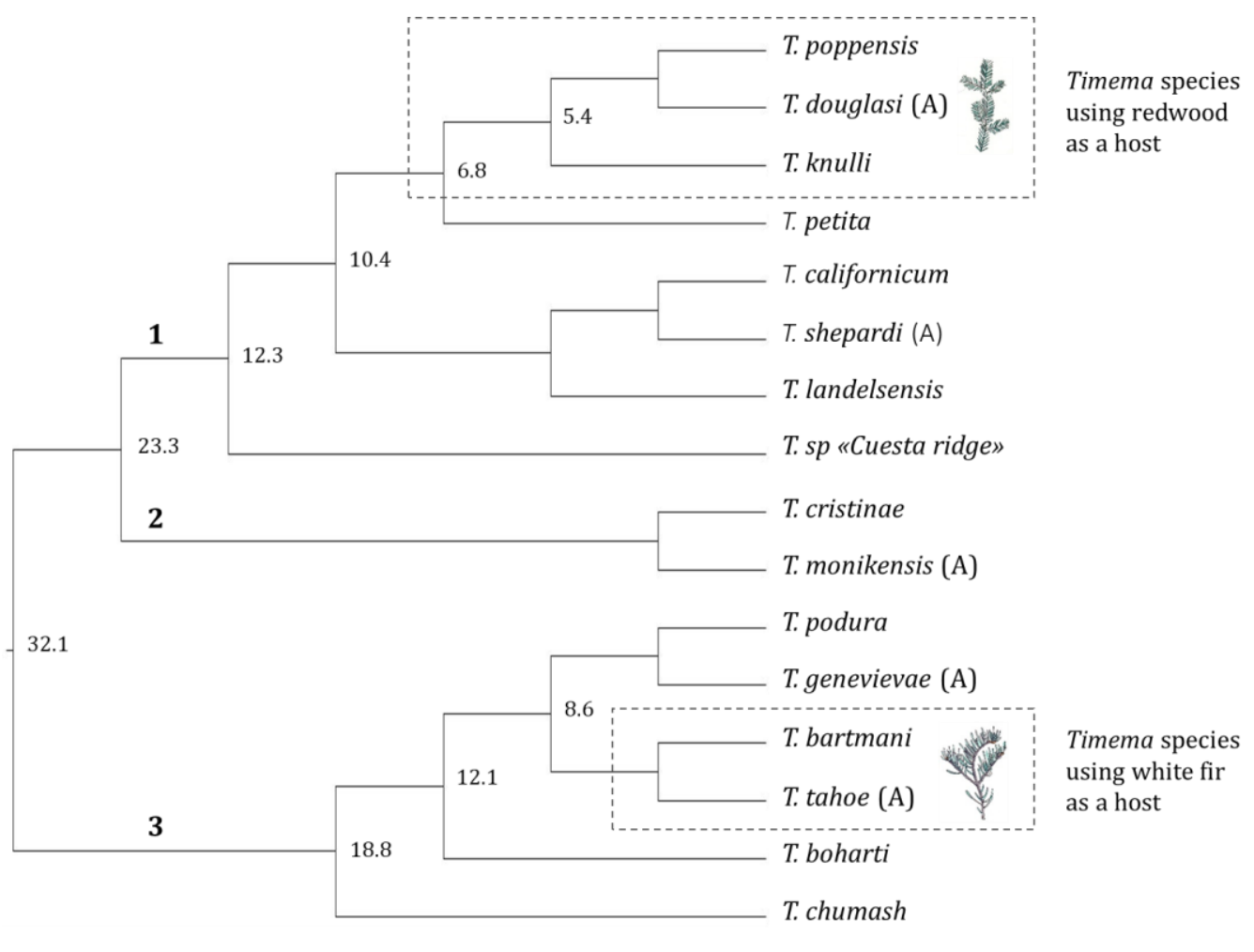

5 Figure 1. Timema phylogeny highlighting the species using the novel host plants redwood

6 and white fir. Phylogeny redrawn from Riesch et al. 2017, with asexual lineages (A) added

7 from Schwander et al. 2011. The phylogenetic position for the missing Timema species (see

8 Table 1) is not known. Bold numbers 1, 2 and 3 correspond to the three described Timema

9 clades, respectively Northern, Santa Barbara, and Southern clade. Node ages (Mya) are from

Riesch et al. 2017. 


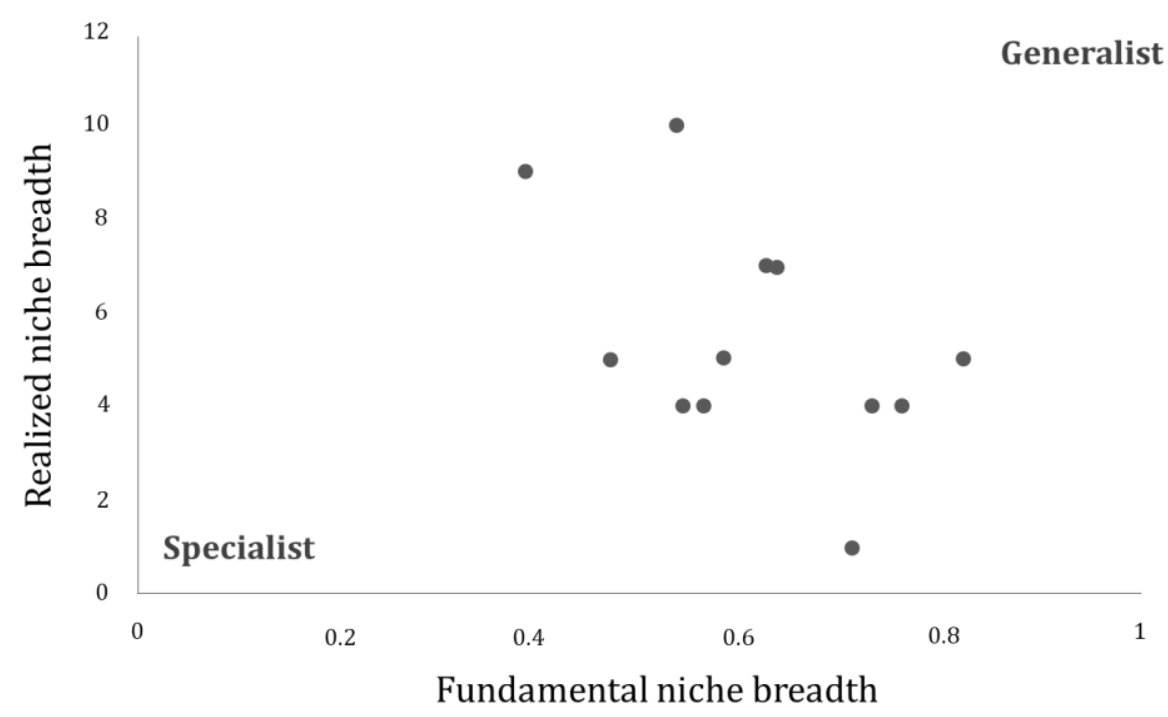

12 Figure 2. The size of the fundamental feeding niche does not constrain the realized feeding

13 niche in Timema. Each point corresponds to a Timema population. For each population, the 14 realized feeding niche breadth is estimated by the number of plant families used by the species, 15 and the breadth of the fundamental feeding niche is estimated using the Tau index (based on 16 insect weight gain). 
A.

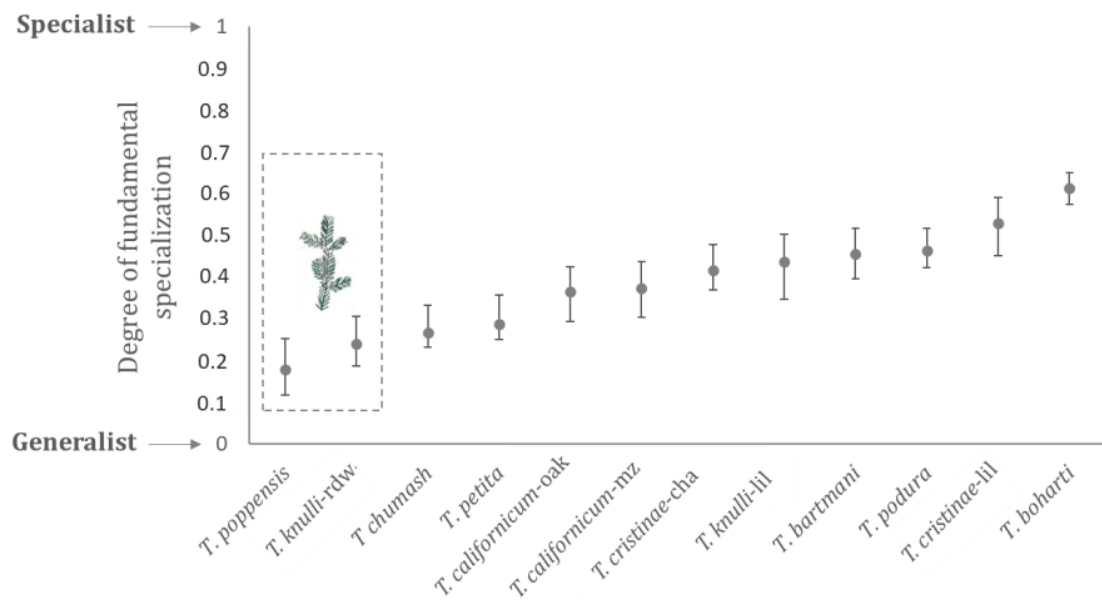

B.

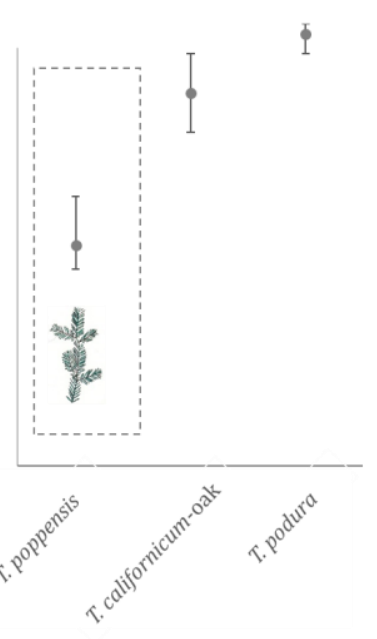

Figure 3. Breadth of the fundamental feeding niche of herbivorous stick insects. Niche

breadth is quantified via the specificity index Tau (with 95\% CI), based on insect weight gain on different plants (other measurements of specialization generate the same outcome, see Figures. S3, S4). The insect populations are listed from the least to the most specialist. Two independent analyses of specificity are presented. In the first one (A), the degree of

24 specialization of twelve populations is based on their performance on seven plants from the 25 Timema host plant pool. In the second one (B), the degree of specialization of a subset of 26 populations is based on their performance on three novel plants not used by Timema stick insects in natural populations (sugar sumac, coyote bush and sage bush). The dotted rectangles highlight populations native to redwood. 
Populations that still use the ancestral angiosperm hosts are affected by similar plant chemical compounds

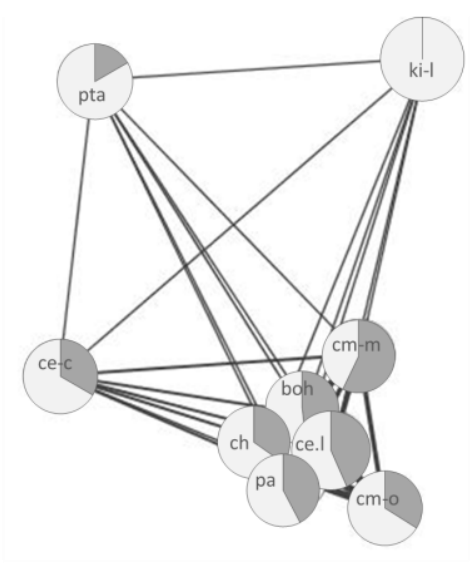

Populations that shifted to the conifer redwood are affected by distinct plant compounds

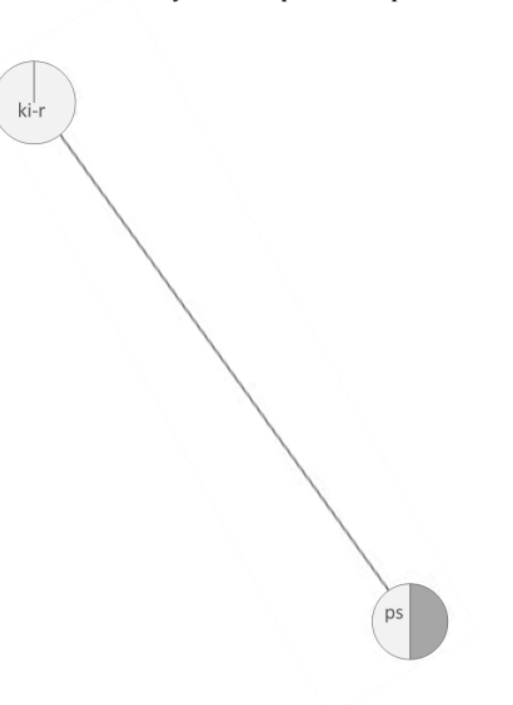

The tested population that shifted to the conifer white fir is affected by distinct and unique plant compounds

Figure 4. Similar plant chemical compounds affect the performance of insects native to

to conifers. Network built with Cytoscape 3.5.1 (Shannon et al. 2003). Circles in the network correspond to the twelve studied Timema populations. The length of the edges connecting two populations is negatively proportional to the number of shared compounds affecting insect weight gain (the more populations are affected by similar compounds the closer they are). The dashed lines separate groups of populations that are not affected by overlapping chemical compounds. Timema population name abbreviations are: bi: T. bartmani from white fir; boh: $T$. boharti from mahogany; cm-m: T. californicum from manzanita; cm-o: T. californicum from oak; ce-c: T. cristinae from chamise; ce-1: T. cristinae from lilac; ch: T. chumash from mahogany; ki-l: T. knulli from lilac; ki-r: T. knulli from redwood; pa: T. podura from chamise; ps: T. poppensis from redwood, pta: T. petita from lilac. 


\section{Supporting Information}

\section{Appendix S1. Detailed methods for plant chemical profile characterization}

We extracted and quantified compounds in the phenolic and terpene classes of secondary metabolites from leaves of the seven plant species included in our experiments (i.e., lil, cha, oak, mz, df, wf, rdw; see Table 1), using methods adapted from (Pratt et al. 2014) and from (Moreira et al. 2015), for terpenes and phenolics, respectively. For each plant species, we extracted compounds from five independent replicates for both phenols and terpenes. Leave samples for terpene extractions were stored in the freezer $\left(-20^{\circ} \mathrm{C}\right)$ prior to use, while samples for phenol extractions were dried in an oven at $45^{\circ} \mathrm{C}$ for one week.

For phenol analyses, $100 \mathrm{mg}$ of dried leaves per sample were reduced to powder with a pestle in liquid nitrogen, and phenols were extracted in $5 \mathrm{ml}$ pure methanol (Sigma-Aldrich, CAS number 67-56-1). The methanolic solutions were kept at room temperature for 1 hour with continuous shaking. Thereafter, the extracts were sonicated for 10 minutes. Twenty-four hours later the tubes were centrifuged at $8000 \mathrm{rpm}$ for 10 minutes and filtered. The collected supernatants were stored at $4^{\circ} \mathrm{C}$ until further use. Samples were analyzed by HPLC using a Grace C18 reversed phase column $(3 \mu \mathrm{m}, 150 \times 4.6 \mathrm{~mm}$; Grace Davison Discovery Science, Columbia, MD, USA) and an YL9100 instrument with diode array detection (YL Instrument Co., Anyang, Korea). The $15 \mu \mathrm{L}$ injection was eluted at a constant flow of $0.7 \mathrm{~mL}$ min-1 with a gradient of acetonitrile and $0.25 \%$ phosphoric acid in water as follows: from $80 \%$ to $50 \%$ water in $5 \mathrm{~min}$, then form $50 \%$ to $30 \%$ in $5 \mathrm{~min}$, and kept at $30 \%$ for $7 \mathrm{~min}$, and a final step from $30 \%$ to $5 \%$ in $4 \mathrm{~min}$, followed by $5 \mathrm{~min}$ of equilibration time. Peaks were detected by a diode array detector at $270 \mathrm{~nm}$ (for hydrolizable tannins), $320 \mathrm{~nm}$ (for ferrulic acid derivates), $370 \mathrm{~nm}$ (for flavonoids) and $500 \mathrm{~nm}$ (for anthocyanins). Absorbance spectra were recorded from 200 to $900 \mathrm{~nm}$. Peaks showing a characteristic absorption band of phenolics (Marbry et al. 1970) were recorded. Concentrations were calculated by using a standard curve that related peak areas to known gallic acid (for hydrolizable tannins), caffeic acid (for caffeic acid derivatives), quercitin (for flavonoids) and cyanidin (for anthocyanins) concentrations using $270 \mathrm{~nm}$ absorbance.

For terpene extractions, plant material was finely ground in liquid nitrogen and $250 \mathrm{mg}$ were used for extraction in $2 \mathrm{~mL}$ n-hexane (Sigma-Aldrich, CAS number 110-54-3), with $20 \square 1$ internal standard (IS) added (tetraline; Sigma-Aldrich, CAS number: 119-64-2, 198 ng in $10 \square 1$ hexane). Five $\square$ l of each sample were subsequently injected into a GC-MS (Agilent 6890 Gas Chromatograph coupled with a 5973N Mass Selective Detector; Agilent, Santa Clara, CA, USA) fitted with a $30 \mathrm{~m} 90.25 \mathrm{~mm} 90.25 \mathrm{~lm}$ film thickness HP-5MS fused silica column (Agilent). We operated the GC in splitless mode with helium as the carrier gas (flow rate $1 \mathrm{ml}$ min-1). The GC oven temperature program was: $1 \mathrm{~min}$ hold at $50^{\circ} \mathrm{C}, 10^{\circ} \mathrm{C}$ min- $1 \mathrm{ramp}$ to $130^{\circ} \mathrm{C}, 5^{\circ} \mathrm{C}$ min- 1 ramp to $180^{\circ} \mathrm{C}, 20^{\circ} \mathrm{C}$ min- 1 ramp to $230^{\circ} \mathrm{C}$ and 1 min hold at $300^{\circ} \mathrm{C}$. We identified terpenes using Kovats retention index from published work (Loayza et al. 1995) and by comparison with commercial standards when available. We measured the richness (total number of compounds) and total production of individual compounds as a proportion to the IS.

Loayza, I., Abujder, D., Aranda, R., Jakupovic, J., Collin, G., Deslauriers, H., et al. (1995). Essential oils of Baccharis salicifolia, B. latifolia and B. dracunculifolia. Phytochemistry, 38, 381-389.

Marbry, T.J., Markham, K.R. \& Thomas, M.B. (1970). The systematic identification of flavonoids. Library of Congress Catalog Card (No. 72-95565).

Moreira, X., Abdala-Roberts, L., Hernández-Cumplido, J., Rasmann, S., Kenyon, S.G. \& Benrey, B. (2015). Plant species variation in bottom-up effects across three trophic levels: A test of traits and mechanisms. Ecol. Entomol., 40, 676-686.

Pratt, J.D., Keefover-Ring, K., Liu, L.Y. \& Mooney, K.A. (2014). Genetically based latitudinal variation in Artemisia california secondary chemistry. Oikos, 123, 953-963. 
94 Table S1. Sampled populations of nine Timema species. The number of individuals refers to the total number of individuals sampled in these locations on different host plants. For plant name abbreviations, see Table 1 in the main text.

\begin{tabular}{|c|c|c|}
\hline Timema species & Location name (GPS coordinates) & $\begin{array}{l}\text { Number of individuals per host } \\
\text { plant sampled }\end{array}$ \\
\hline T. bartmani & 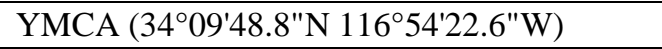 & 0 oak, 0 pin, $350 \mathrm{wf}$ \\
\hline T. boharti & Sunrise $\left(32^{\circ} 58^{\prime} 40.6^{\prime \prime N} 116^{\circ} 31^{\prime} 27.7^{\prime \prime W}\right)$ & 0 ad, 130 cer, 0 oak \\
\hline T. californicum & $\begin{array}{l}\text { Skyline }\left(37^{\circ} 14^{\prime} 43.6^{\prime \prime} \mathrm{N} 122^{\circ} 06^{\prime} 37.0^{\prime \prime} \mathrm{W}\right) \\
\text { Saratoga }\left(37^{\circ} 11^{\prime} 47.0^{\prime \prime} \mathrm{N} 122^{\circ} 02^{\prime} 27.1^{\prime \prime} \mathrm{W}\right) \\
\text { Summit }\left(37^{\circ} 02^{\prime} 43.2^{\prime \prime N} 121^{\circ} 45^{\prime} 11.6^{\prime \prime} \mathrm{W}\right) \\
\end{array}$ & $\begin{array}{l}2 \mathrm{ad}, 18 \mathrm{mz}, 43 \text { oak } \\
4 \mathrm{ad}, 12 \mathrm{mz}, 4 \text { oak } \\
51 \mathrm{mz}, 0 \text { oak, } 0 \text { rdw }\end{array}$ \\
\hline T. chumash & 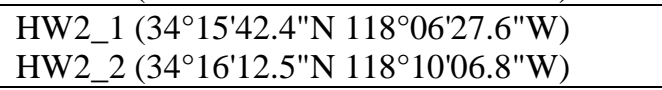 & $\begin{array}{l}45 \text { cea, } 70 \text { cer, } 250 \text { oak } \\
18 \text { ad, } 5 \text { cea, } 11 \text { oak }\end{array}$ \\
\hline T. cristinae & $\begin{array}{l}\text { Ojai1 }\left(34^{\circ} 31^{\prime} 01.7^{\prime \prime} \mathrm{N} 119^{\circ} 16^{\prime} 39.7^{\prime \prime} \mathrm{W}\right) \\
\text { Ojai2 }\left(34^{\circ} 30^{\prime} 20.0^{\prime \prime} \mathrm{N} 119^{\circ} 16^{\prime} 47.5^{\prime \prime} \mathrm{W}\right) \\
\text { Ojai3 }\left(34^{\circ} 31^{\prime} 59.6^{\prime \prime N} 119^{\circ} 14^{\prime} 51.8^{\prime \prime} \mathrm{W}\right) \\
\text { WTA1 }\left(34^{\circ} 30^{\prime} 46.6^{\prime \prime N} 119^{\circ} 46^{\prime} 41.7^{\prime \prime W}\right) \\
\text { WTA2 }\left(34^{\circ} 30^{\prime} 22.3^{\prime \prime N} 119^{\circ} 46^{\prime} 05.3^{\prime \prime} \mathrm{W}\right) \\
\text { WTA3 }\left(34^{\circ} 30^{\prime} 56.8^{\prime \prime N} 119^{\circ} 46^{\prime} 43.7^{\prime \prime} \mathrm{W}\right)\end{array}$ & $\begin{array}{l}245 \text { cea, } 73 \text { cer, } 6 \mathrm{mz}, 70 \text { oak, } 5 \text { toy } \\
23 \text { cea, } 62 \text { cer, } 11 \mathrm{mz}, 28 \text { oak } \\
8 \mathrm{ad}, 2 \text { cea, } 20 \text { cer, } 8 \text { oak } \\
597 \mathrm{ad}, 317 \text { cer, } 78 \text { oak } \\
81 \mathrm{ad}, 1 \text { cer, } 8 \mathrm{mz}, 9 \text { oak, } 2 \text { toy } \\
60 \mathrm{ad}, 24 \text { cea, } 5 \mathrm{mz}, 7 \text { toy }\end{array}$ \\
\hline T. knulli & 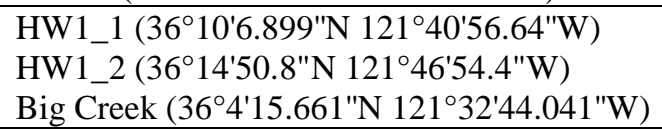 & $\begin{array}{l}0 \text { ad, } 9 \text { cea, } 0 \text { oak, } 0 \mathrm{rdw} \\
0 \text { cea, } 0 \text { oak, } 13 \mathrm{rdw} \\
12 \text { cea, } 0 \mathrm{mz}, 0 \text { oak, } 0 \mathrm{rdw}\end{array}$ \\
\hline T. petita & HW1_3 (36²9'10.0"N 121 55 '56.2"W) & 330 cea, $3 \mathrm{mz}, 0$ oak \\
\hline T. podura & $\begin{array}{l}\text { Indian }\left(33^{\circ} 47^{\prime} 50.5^{\prime \prime N} 116^{\circ} 46^{\prime} 35.5^{\prime \prime} \mathrm{W}\right) \\
\text { Poppet }\left(33^{\circ} 51^{\prime} 36.9^{\prime \prime} \mathrm{N} 116^{\circ} 50^{\prime} 20.4^{\prime \prime} \mathrm{W}\right)\end{array}$ & $\begin{array}{l}79 \mathrm{ad}, 60 \text { cea, } 0 \text { cer, } 7 \mathrm{mz}, 0 \text { oak } \\
45 \mathrm{ad}, 0 \text { cea, } 0 \mathrm{mz}\end{array}$ \\
\hline T. poppensis & $\begin{array}{l}\text { Fish_Rock }\left(38^{\circ} 49^{\prime} 05.1^{\prime \prime} \mathrm{N} 123^{\circ} 35^{\prime} 03.5^{\prime \prime} \mathrm{W}\right) \\
\text { Bear Creek }\left(37^{\circ} 09^{\prime} 56.2^{\prime \prime} \mathrm{N} 122^{\circ} 00^{\prime} 56.4^{\prime \prime} \mathrm{W}\right) \\
\text { Madonna }\left(37^{\circ} 01^{\prime} 07.5^{\prime \prime} \mathrm{N} 121^{\circ} 43^{\prime} 32.0^{\prime \prime} \mathrm{W}\right)\end{array}$ & $\begin{array}{l}0 \text { cea, } 137 \mathrm{df}, 14 \mathrm{rdw} \\
85 \mathrm{df}, 0 \text { oak, } 35 \mathrm{rdw} \\
0 \mathrm{mz}, 0 \text { oak, } 403 \mathrm{rdw}\end{array}$ \\
\hline
\end{tabular}


Table S2. Relative survival of Timema individuals on different plants during ten days. For each Timema population, the survival on the native host plant is highlighted in grey. In the case of $T$. boharti and $T$. chumash the survival on their native host plant (Cercocarpus betuloides) is unknown as this plant was not included in the experiments. The proportion of deviance accounted for by the different plants in the GLMs was calculated using the modEva R package (Barbosa et al. 2013); Pearson's chi-squared tests were performed to test whether plants explain a significant amount of deviance (p-value $<0.001$ : $* * * ;<0.01: * * ;<0.05: *)$. For plant name abbreviations, see Table 1 in the main text.

\begin{tabular}{|c|c|c|c|c|c|c|c|c|c|c|}
\hline Timema species & $\begin{array}{l}\text { Sample } \\
\text { size per } \\
\text { treatment }\end{array}$ & lil & cha & oak & $\mathrm{mz}$ & $\mathrm{df}$ & wf & $\mathrm{rdw}$ & $\begin{array}{l}\% \text { of deviance } \\
\text { explained }\end{array}$ & $\mathrm{p}$-value \\
\hline T. bartmani & 14 to 80 & 100.0 & 52.5 & 0.0 & 37.7 & 37,7 & 35.4 & 0.0 & 18.0 & $6.0 \mathrm{e}-07 * * *$ \\
\hline T. boharti & 10 & 100.0 & 88.9 & 55.6 & 33.3 & 22.2 & 0.0 & 0.0 & 43.7 & $9.3 \mathrm{e}-06^{* * *}$ \\
\hline T. californicum-mz & 10 & 90.0 & 100.0 & 100.0 & 90.0 & 70.0 & 50.0 & 10.0 & 42.1 & $2.4 \mathrm{e}-06^{* * *}$ \\
\hline T. californicum-oak & 10 to 20 & 100.0 & 100.0 & 100.0 & 100.0 & 100.0 & 80.0 & 50.0 & 47.5 & $4.3 \mathrm{e}-04 * * *$ \\
\hline T. chumash & 10 & 88.9 & 100.0 & 88.9 & 100.0 & 55.6 & 77.8 & 55.6 & 10.9 & 0.18 \\
\hline T. cristinae-cha & 10 & 100.0 & 87.5 & 25.0 & 75.0 & 75.0 & 12.5 & 0.0 & 44.7 & $2.3 \mathrm{e}-05^{* * *}$ \\
\hline T. cristinae-lil & 10 & 100.0 & 100.0 & 57.9 & 84.2 & 34.7 & 28.9 & 11.6 & 31.3 & $3.3 \mathrm{e}-04 * * *$ \\
\hline T. knulli-lil & 10 to 20 & 100.0 & 100.0 & 26.7 & 93.3 & 26.7 & 26.7 & 6.7 & 29.7 & $3.9 \mathrm{e}-07 * * *$ \\
\hline T. knulli-rdw & 24 & 90.5 & 86.7 & 71.4 & 77.5 & 100.0 & 82.1 & 86.7 & 3.9 & 0.36 \\
\hline T. petita & 10 & 100.0 & 90.0 & 20.0 & 90.0 & 30.0 & 30.0 & 10.0 & 34.1 & $4.7 \mathrm{e}-05^{* * *}$ \\
\hline T. podura & 15 & 76.9 & 100.0 & 23.1 & 92.3 & 23.1 & 7.7 & 0.0 & 41.1 & $4.7 \mathrm{e}-09 * * *$ \\
\hline T. poppensis & 30 & 92.9 & 85.7 & 60.7 & 78.6 & 100 & 64.3 & 75.0 & 7.6 & $0.009 * *$ \\
\hline
\end{tabular}
analysis. 

To measure the performance of insects on different plants, the collected juveniles were transferred to 50mL Falcon tubes containing a branch, with the broken end immersed in a water reservoir. Prior to the transfer, individual insects were weighed with an analytical balance (Kern ABT 120-5DM). During the ten days of the experiment, all tubes were observed daily to verify the survival of individuals and individuals that survived were weighted again at the end of the

118 experiment. 

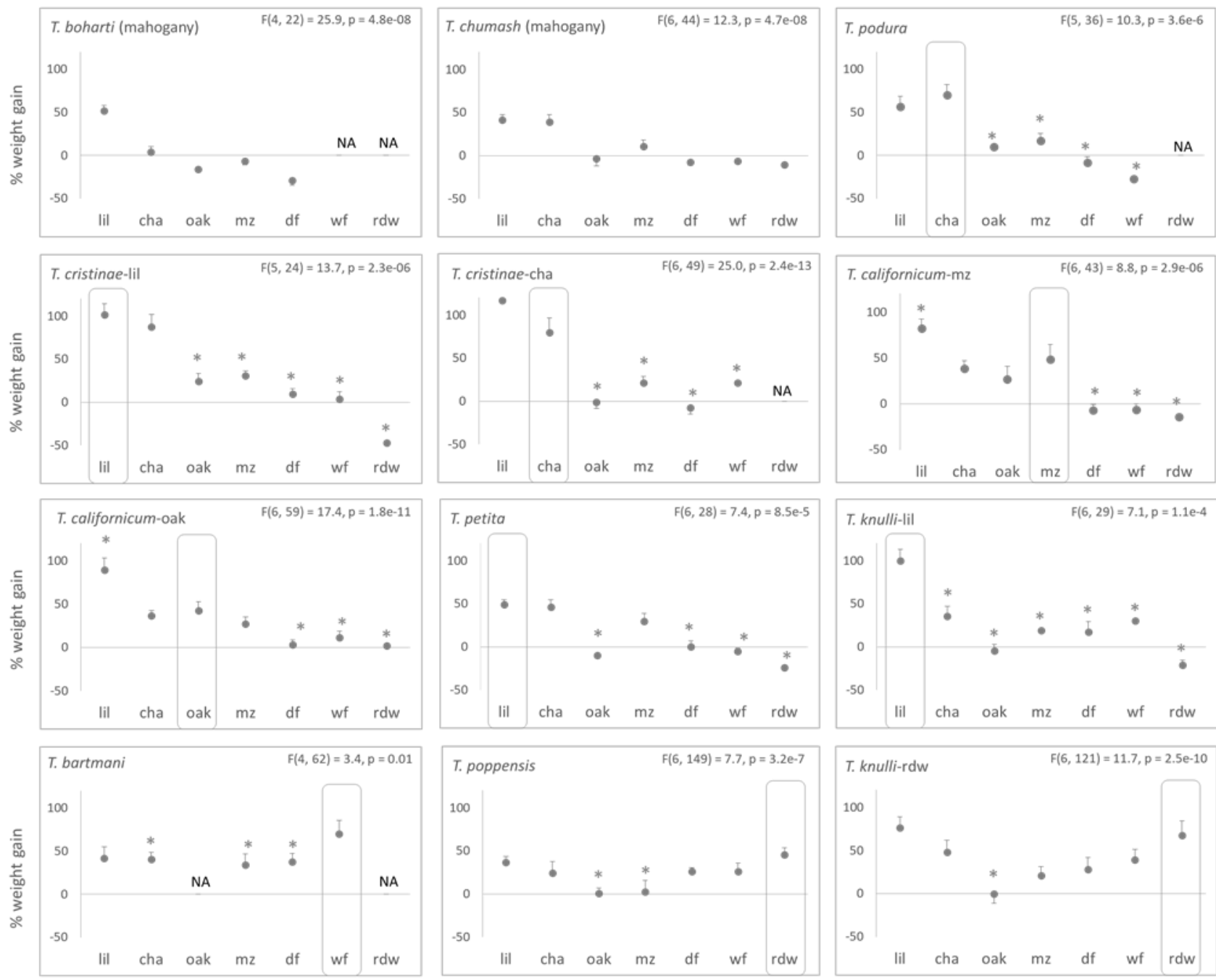

Host plants

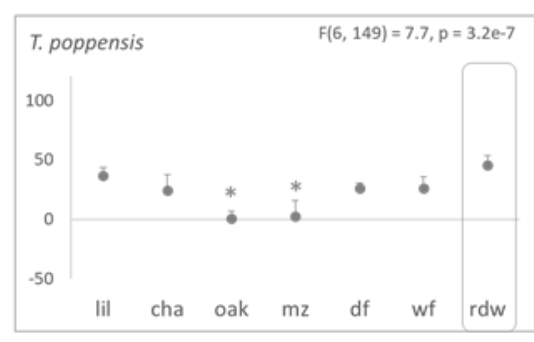

Host plants

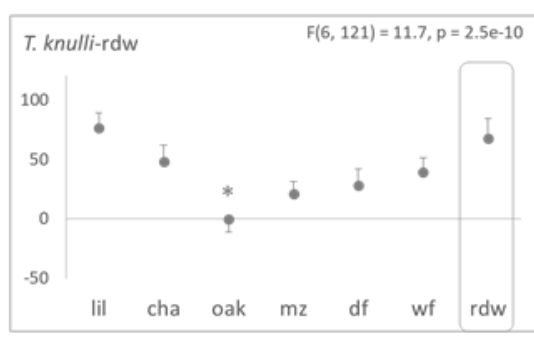

Host plants

120 Figure S2. Percentages of weight gain for individuals fed with different plants for ten days.

121 Each panel corresponds to a different Timema population, rectangles indicate native hosts. For each population, the amount of weight gained by individuals that survived during ten days on the different plants was compared using one-way ANOVAs. The asterisks indicate the plants on which the performance is significantly different from their performance on the native host (planned comparisons; * significant at $\mathrm{p}<0.05$ ). For some plant by Timema population combinations, there are no weight gain data (NA) because all individuals died before the end of the experiment. For plant name abbreviations, see Table 1 in the main text. 

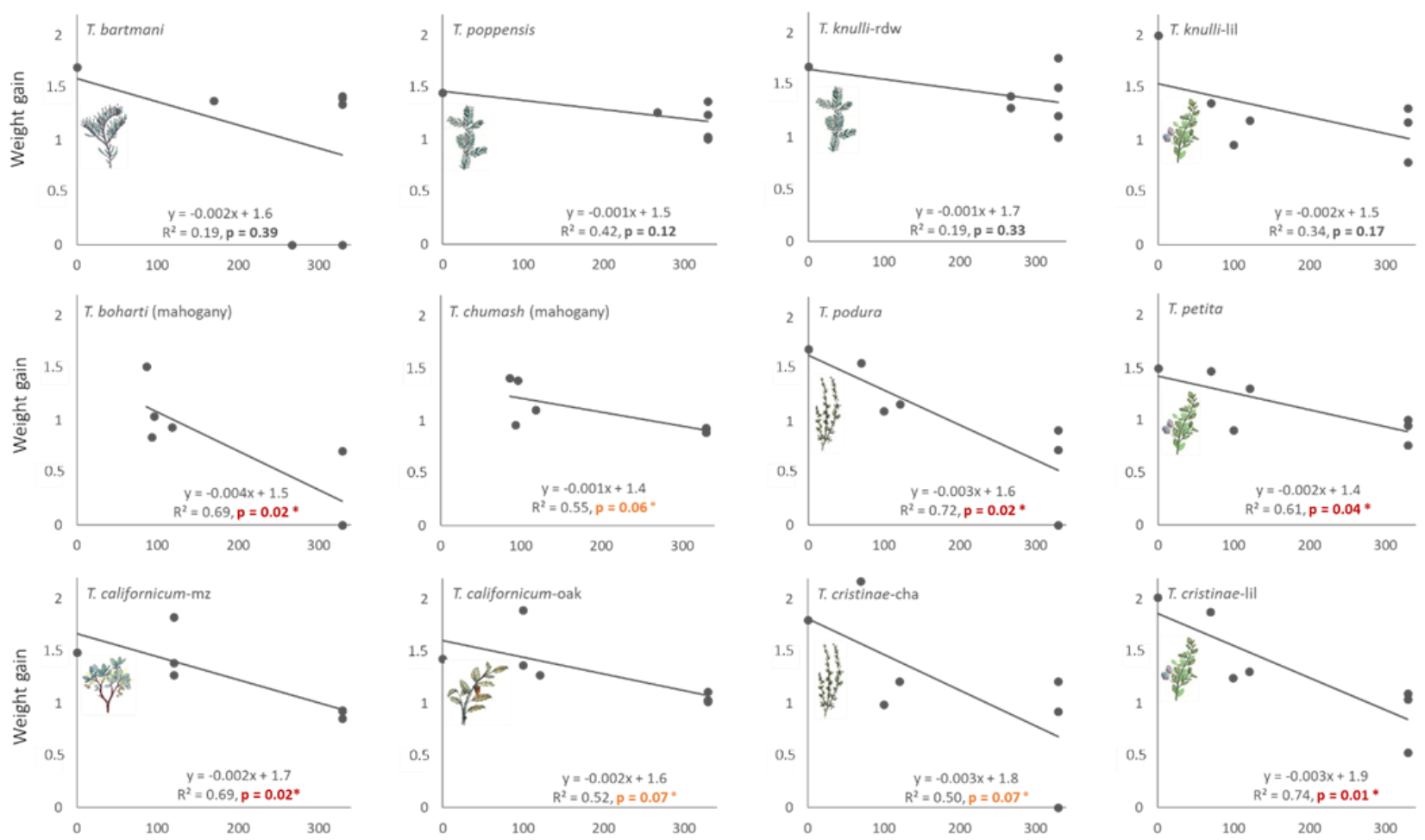

Phylogenetic distance of the experimental plant species to the native host species

Figure S3. Relative weight gain of Timema individuals as a function of the phylogenetic distance between the native host plant and the plants used in the experiments. Native plants are indicated with icons (except for T. boharti and T. chumash where the performance on native hosts was not evaluated, see main text). Phylogenetic distances between plants are from Table 1 in the main text. Steeper slopes indicate more extensive specialization.

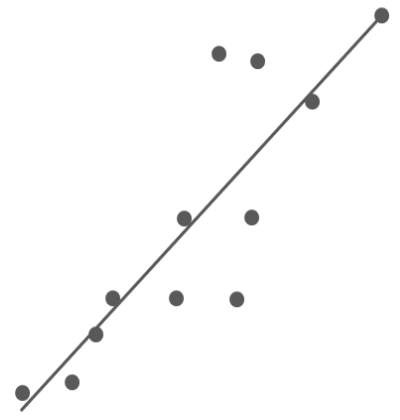

No effect of plant-relatedness

$\rightarrow 0$ on insect performance
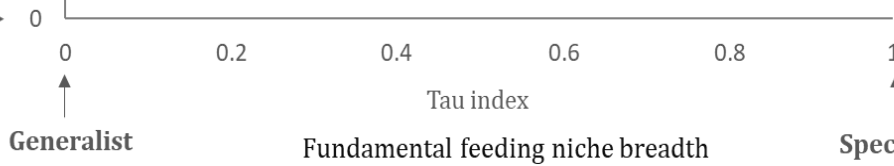

Fundamental feeding niche breadth

Specialist

Figure S4. Correlation between two independent estimates of the degree of fundamental niche specialization. Each point corresponds to a Timema population. The Y-axis measures the performance decay of insects when fed with plants phylogenetically distant from the native host (slopes from Figure S5), the X-axis quantifies the specialization of insects via the Tau index. PGLS; r: $-0.78, \mathrm{p}=0.025$. 


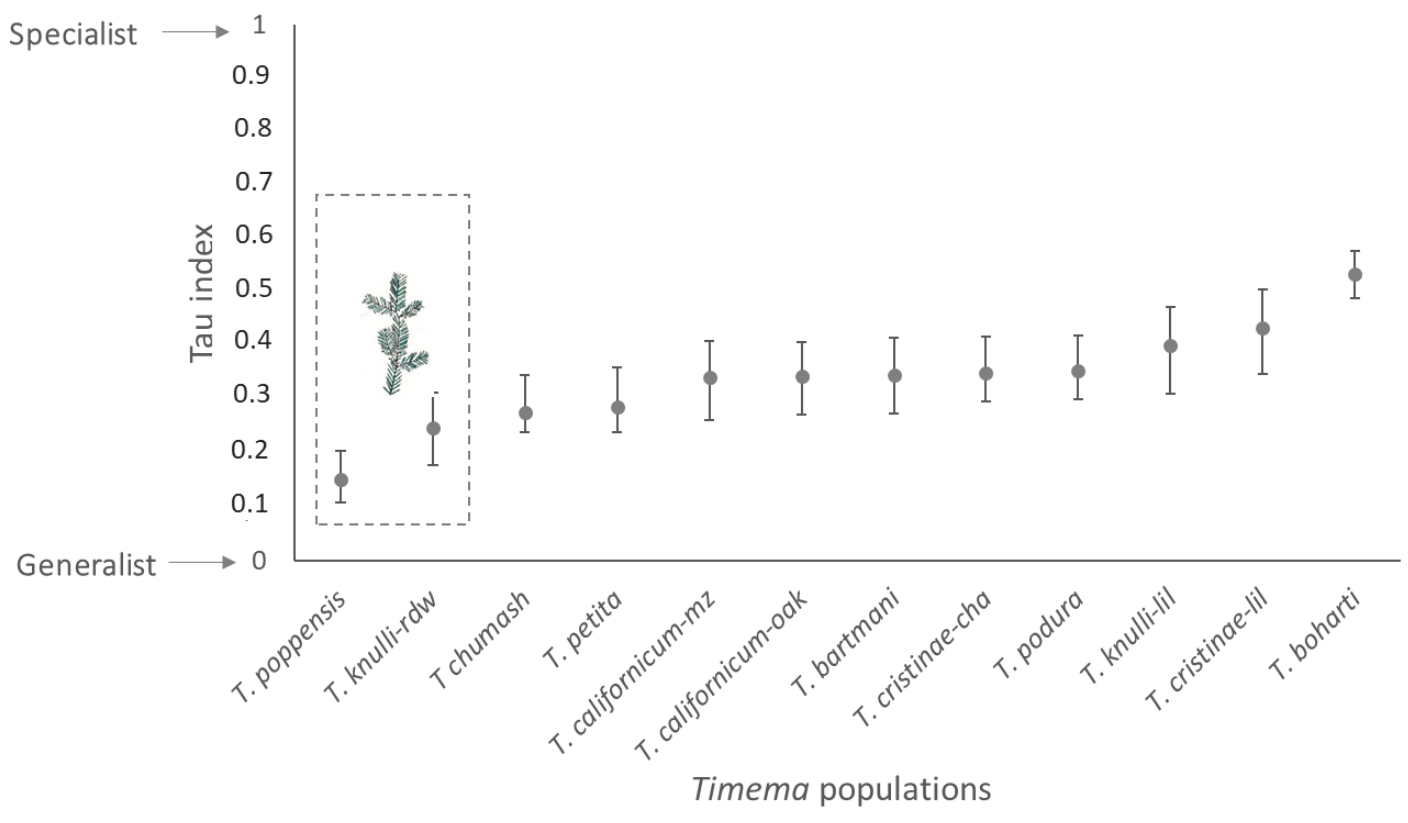

Figure S5. Breadth of the fundamental feeding niche of Timema from multiple populations. Niche breadth is quantified via the specificity index Tau (with 95\% CI), based on insect weight gain on different plants (data from redwood excluded). The insect populations are listed from the least to the most specialist; $T$. poppensis and $T$. knulli native to redwood remain the most generalist populations even if data from redwood are excluded.

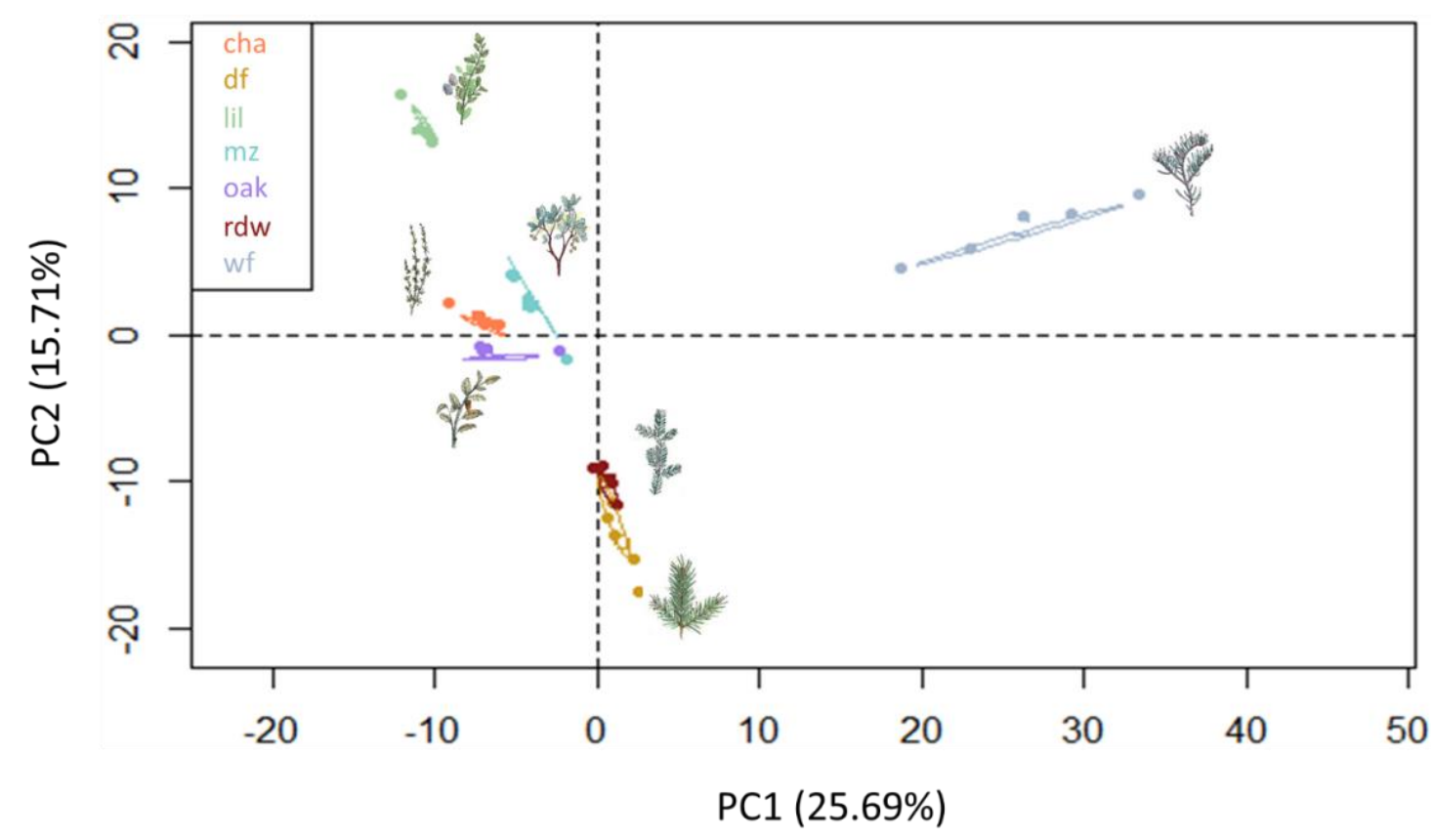

Figure S6. Principal component analysis based on the 521 plant chemical compounds (28 phenolic and 493 terpenic compounds). Percentages indicate the amount of variance explained by each axis. For plant name abbreviations, see Table 1 in the main text. 


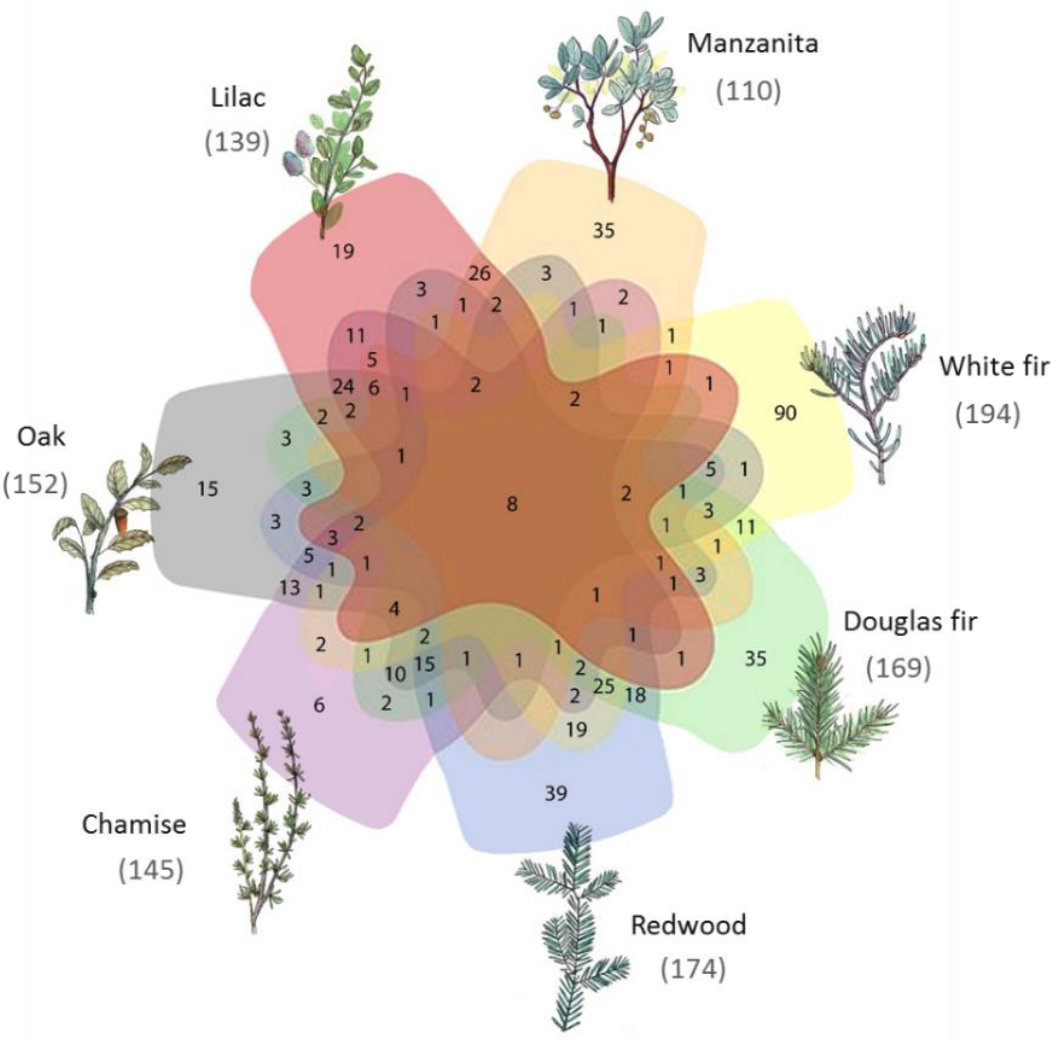

157 Figure S7. Specific and shared chemical compounds of different Timema host plants. The 158 numbers in the Venn diagram indicate the number of terpenic and phenolic compounds shared 159 among sets of plants and the number of species specific ones. Numbers in brackets indicate the 160 total number of chemical compounds present in each plant. 